\title{
Sorbent Material Property Requirements for On-Board Hydrogen Storage for Automotive Fuel Cell Systems
}

\author{
R. K. Ahluwalia ${ }^{1}$ J-K Peng and T. Q. Hua
}

Argonne National Laboratory, 9700 S Cass Avenue, Argonne, IL 60439, USA

Material properties required for on-board hydrogen storage in cryogenic sorbents for use with automotive polymer electrolyte membrane (PEM) fuel cell systems are discussed. Models are formulated for physical, thermodynamic and transport properties, and for the dynamics of $\mathrm{H}_{2}$ refueling and discharge from a sorbent bed. A conceptual storage configuration with in-bed heat exchanger tubes, a Type-3 containment vessel, vacuum insulation and requisite balance-of-plant components is developed to determine the peak excess sorption capacity and differential enthalpy of adsorption for $5.5 \mathrm{wt} \%$ system gravimetric capacity and 55\% well-to-tank (WTT) efficiency. The analysis also determines the bulk density to which the material must be compacted for the storage system to reach 40 g. $\mathrm{L}^{-1}$ volumetric capacity. Thermal transport properties and heat transfer enhancement methods are analyzed to estimate the material thermal conductivity needed to achieve $1.5 \mathrm{~kg} \cdot \mathrm{min}^{-1} \mathrm{H}_{2}$ refueling rate. Operating temperatures and pressures are determined for 55\% WTT efficiency and 95\% usable $\mathrm{H}_{2}$. Needs for further improvements in material properties are analyzed that would allow reduction of storage pressure to $50 \mathrm{bar}$ from $100 \mathrm{bar}$, elevation of storage temperature to $175-200 \mathrm{~K}$ from $150 \mathrm{~K}$, and increase of WTT efficiency to $57.5 \%$ or higher.

Keywords: Micro-porous sorbents; Sorption isotherms; Hydrogen storage systems;

Thermodynamics of sorption; Heat transfer

${ }^{1}$ Corresponding author: walia@anl.gov, 1-630-252-5979 


\section{Nomenclature}

\begin{tabular}{llll}
$C, C_{p}$ & specific heat & \multicolumn{2}{c}{$C, E, K_{i} \quad$ Langmuir isotherm constants } \\
$d$ & diameter & $\varepsilon$ & fill factor \\
$\varepsilon_{v}$ & pore volume fraction & $f$ & fugacity \\
$h$ & enthalpy & $H$ & integral enthalpy \\
$l$ & length of tubes & $m$ & mass \\
$\dot{m}$ & mass flow rate & $\mathrm{N}$ & amount of adsorption \\
$n$ & number of tubes & $P$ & absolute pressure \\
$\dot{Q}$ & heat transfer rate & $R$ & gas constant, thermal resistance \\
$T$ & temperature & $t$ & time \\
$u$ & internal energy & $v_{a}$ & adsorption volume \\
$V_{m}$ & volume of storage medium & $V_{s t}$ & inside volume of storage tank \\
$z$ & compressibility factor & $\Delta h$ & heat of adsorption \\
$\Delta s_{a}$ & entropy of adsorption & $\alpha$ & fraction of active sites \\
$\beta$ & isobaric compressibility & $\varepsilon$ & material fill factor \\
$\kappa$ & isothermal compressibility & $\lambda$ & thermal conductivity \\
$\rho$ & density & $\theta$ & coverage
\end{tabular}

\section{Subscripts/Superscripts}

$\begin{array}{llll}a & \text { absolute adsorption } & b & \text { bulk } \\ e & \text { excess } & E G & \text { expanded natural graphite } \\ f & \text { coolant } & g & \text { gas } \\ \text { in } & \text { inlet } & m & \text { medium } \\ o & \text { perfect gas } & \text { out } & \text { outlet } \\ s & \text { sorbent } & \mathrm{S} & \text { structure } \\ x & \text { heat exchanger } & & \end{array}$

*Some variables are identified within the text for clarity. 


\section{Introduction}

Physisorption in sorbents offers many potential advantages as a hydrogen storage option for fuel cell vehicles. Compared to the near-term compressed $\mathrm{H}_{2}$ storage at 700 bar, the storage pressure for sorbent systems can be much lower without a significant reduction in capacity. Compared to the liquid and cryo-compressed options, the storage temperatures with sorbents can be higher, thus reducing the cost for insulation and the energy consumption for cooling. Compared to the metal hydride options, the sorption kinetics is fast, allowing rapid $\mathrm{H}_{2}$ refueling and discharge; the much smaller enthalpy of sorption eases thermal management requirements; and the on-board system efficiency can be approach $100 \%$. Sorption is a completely reversible process and does not require off-board regeneration as is needed for chemical hydrogen storage options. The main challenge for sorbents is their low binding energies for $\mathrm{H}_{2}$ which can be overcome by using cryogenic temperatures to enhance their gravimetric and volumetric storage capacities.

Various materials have been investigated as sorbents for hydrogen. Superactivated carbon is generally regarded as the baseline material that serves as the reference for benchmarking the capacity of other adsorbents. Commercially available activated carbons, such as Maxsorb and AX-21, can have 2500-3000 $\mathrm{m}^{2} \cdot \mathrm{g}^{-1}$ specific surface area (SSA) and peak excess $\mathrm{H}_{2}$ uptake that is only $\sim 1 \mathrm{wt} \%$ at room temperature, although increases to $5.4 \mathrm{wt} \%$ at $77 \mathrm{~K}$ for pressures at 50 bar [1]. On zeolite-templated carbon, this capacity further increases to $6.9 \mathrm{wt} \%$ at $77 \mathrm{~K}$ and $20 \mathrm{bar}$ [2]. Since the gravimetric capacity of pure physisorption-based materials scales with SSA, attempts have been made to increase the surface area by optimizing the pore size distribution, recognizing that 0.7 to $1.5 \mathrm{~nm}$ pores are desirable [3]. For example, carbon aerogels have been fabricated with BET surface areas up to $3200 \mathrm{~m}^{2}$. $\mathrm{g}^{-1}$, but $\mathrm{H}_{2}$ uptake at $77 \mathrm{~K}$ was still $<5.2 \mathrm{wt} \%$ [4]. According to Simpson [3], substantial increase in capacity may not be achievable with 
enhancement in geometric surface area alone, and carbon surface may have to be functionalized with metals or other light-weight materials such as boron to increase its binding energy for dihydrogen [5]. Weak chemisorption via "spillover" mechanism is also being evaluated as a technique to increase the performance at ambient conditions by using a catalyst (typically $\mathrm{Pd}, \mathrm{Pt}$, or $\mathrm{Ni)}$ as a promoter [3].

Metal-organic frameworks (MOFs) are a class of crystalline porous nano materials built from metal ions or clusters which form a coordination network with organic ligands. MOFs have very high specific surface area (up to $7140 \mathrm{~m}^{2} \cdot \mathrm{g}^{-1}$ ), ultrahigh porosity (up to $90 \%$ free volume), tunable pore size, and modifiable internal surface [6]. To date, the best performing MOF, NU100, has reportedly achieved $99.5 \mathrm{mg} \cdot \mathrm{g}^{-1}(\sim 9 \mathrm{wt} \%)$ excess adsorption at $77 \mathrm{~K}$ and 56 bar [7]. Research efforts are underway to enhance the binding energy between $\mathrm{H}_{2}$ and the framework from 4-12 kJ.mol ${ }^{-1}$ to $15-20 \mathrm{~kJ} \cdot \mathrm{mol}^{-1}$ and achieve similar adsorption at near ambient conditions (typically $\sim 1 \mathrm{wt} \%$ ) [8]. Some of the strategies being investigated include use of coordinatively unsaturated metal sites, functionalization of ligands, increase in surface area and pore volume, and catenation and control of pore size [6-9].

Covalent organic frameworks (COFs) are another class of crystalline materials built from organic "linkers" which are made up of light elements $(\mathrm{C}, \mathrm{O}, \mathrm{B}$, and $\mathrm{Si})$ and held together by strong covalent bonds. These materials have high surface area and low density, making them attractive candidates for hydrogen storage. Because of their significantly lower density compared to MOFs, COFs have an advantage in the hydrogen gravimetric storage capacity. Theoretical studies using GCMC (grand canonical Monte Carlo) simulations indicate that $>10 \mathrm{wt} \%$ excess $\mathrm{H}_{2}$ uptake at 77 $\mathrm{K}$ and 100 bar is theoretically possible in the three-dimensional COFs (COF-102, $-103,-105$, and -108) [10]. Recent advances [10] in COF synthesis have produced materials with BET surface 
area up to $4210 \mathrm{~m}^{2} \cdot \mathrm{g}^{-1}$ (COF-103), pore volume up to $1.66 \mathrm{~cm}^{3} \cdot \mathrm{g}^{-1}$ (COF-103) and crystalline density as low as 0.17 g.cm ${ }^{-3}$ (COF-18). Furukawa and Yaghi [11] used a high-pressure apparatus to measure the gravimetric capacity of 2D (COF-1, -5, -6, -8 and -10) and 3D (COF102, -103) COFs and experimentally confirmed that the 3D materials have higher capacity. The maximum uptake for 2D COFs ranged from $15 \mathrm{mg} \cdot \mathrm{g}^{-1}$ (COF-1) to $36 \mathrm{mg} \cdot \mathrm{g}^{-1}$ (COF-5). For 3D COFs, the maximum uptake was 74.4 for CFO-102 and $70.5 \mathrm{mg} \cdot \mathrm{g}^{-1}$ for COF-103. Of the two 3D materials, COF-102 had slightly higher measured excess uptake: $\sim 6.75 \mathrm{wt} \%$ at $77 \mathrm{~K}$ and 30 bar. They observed a linear relationship between $\mathrm{H}_{2}$ uptake and pore volume $\left(\mathrm{cm}^{3} \cdot \mathrm{g}^{-1}\right)$ and also higher uptake in micropores $(<2 \mathrm{~nm})$ than in mesopores $(\geq 2 \mathrm{~nm})$.

Porous organic polymers (POPs) are yet another class of hydrogen adsorbents that are light weight, thermally stable, and have high pore volume and high tolerance to moisture. POPs can achieve high volumetric density by compaction and pelletizing without impacting its high surface area. POPs can be manufactured at large scale using existing industrial infrastructure [12], an advantage not matched by COFs although there are efforts being pursued to produce MOFs at large scale. Liu et al. [12] synthesized aromatic, boron-doped hetero-aromatic and transition metal-doped POPs and measured their excess uptake at $77 \mathrm{~K}$ and 40 bar. They reported $5.5 \mathrm{wt} \%$ excess uptake, $6.5 \mathrm{~kJ} \cdot \mathrm{mol}^{-1}$ isosteric heat of adsorption, and $3143 \mathrm{~m}^{2} \cdot \mathrm{g}^{-1}$ BET surface

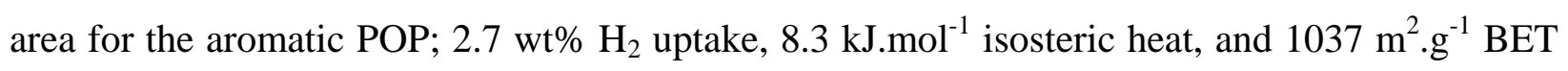

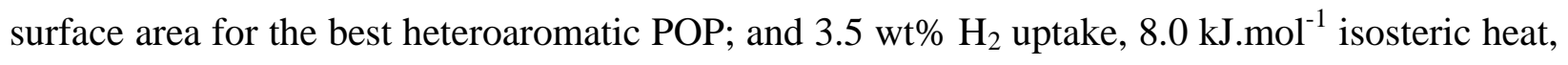
and $1704 \mathrm{~m}^{2} \cdot \mathrm{g}^{-1}$ BET surface area for the best metal-doped POP $[12,13]$.

The objective of this paper is to provide a perspective on the state-of-the-art of sorbent development by establishing material properties that would be required to achieve the system level targets for hydrogen storage for light-duty vehicles. Table 1 is an abbreviated list of the 
performance-related targets that are considered important for hydrogen sorbents, as specified by the U.S. Department of Energy [14]. There are additional important targets for storage system cost, fuel cost, material stability (shelf life and durability over multiple charge-discharge cycles), fuel quality (i.e., purity of $\mathrm{H}_{2}$ from storage system) and environmental health and safety, but they are not specifically addressed here. A critical aspect of this work is to determine the operating conditions such that the storage system meets the overall well-to-powerplant efficiency.

\section{Storage System Model}

In this section, we first discuss a simple adsorption isotherm that adequately describes $\mathrm{H}_{2}$ uptake in sorbents over the useful ranges of pressures and temperatures. We then formulate a method to determine the adsorption thermodynamics using the material-specific parameters that appear in the generalized isotherm. The last part is to couple the thermodynamics to a dynamic model for refueling and discharge of an insulated storage vessel containing the sorbent and in-bed heat transfer tubes for thermal management.

\subsection{Adsorption Isotherms}

Different types of adsorption isotherms have been used to correlate the experimentally measured equilibrium hydrogen uptake on sorbents. For example, in our previous system analysis work [15], following Benard and Chahine [1], we used the Ono-Kondo lattice theory to model the adsorption of hydrogen on superactivated carbon substrate (AX-21) at high pressures and low

temperatures. Beckner and Dailly [16] have shown that the Dubinin-Astakhov (D-A) equation also adequately represents hydrogen adsorption on superactivated carbon and metalorganic frameworks. Recently, Stadie [17] demonstrated that the generalized double-Langmuir equation can accurately describe hydrogen adsorption on superactivated carbon MSC-30 and 
zeolite-templated carbon ZTC-3 at pressures up to 35 bar and temperatures between 77 and 298 K.

For reverse engineering, it is desirable to use an adsorption isotherm with the least number of fitted parameters that are easily related to fundamental material properties. Following Stadie [17], we first used the double-Langmuir equation to fit the data obtained by Zhou et al. [18] and Sudik et al. [19] for excess uptake of $\mathrm{H}_{2}$ on MOF-5 powder (Basolite Z100-H) at 30-300 K and 1-90 bar. Assuming that the two types of adsorption sites are invariant (fixed $\alpha$ ) with different characteristic energies $\left(E_{1}\right.$ and $\left.E_{2}\right)$, and that the specific adsorption volume $\left(v_{a}\right)$ is proportional to coverage, the generalized Langmuir equation reduces to the following for absolute $\left(N_{a}\right)$ and excess $\left(N_{e}\right)$ uptake.

$$
\begin{aligned}
& N_{a}=N_{\max }\left[\alpha\left(\frac{K_{1} P}{1+K_{1} P}\right)+(1-\alpha)\left(\frac{K_{2} P}{1+K_{2} P}\right)\right] \\
& N_{e}=N_{\text {max }}\left(1-v_{a} \rho_{g}\right)\left[\alpha\left(\frac{K_{1} P}{1+K_{1} P}\right)+(1-\alpha)\left(\frac{K_{2} P}{1+K_{2} P}\right)\right] \\
& K_{i}=\frac{C_{i}}{\sqrt{T}} e^{\frac{E_{i}}{R T}}
\end{aligned}
$$

Equations (1)-(3) contain seven empirical parameters: $N_{\max }, \alpha, v_{a}, C_{1}, E_{1}, C_{2}$ and $E_{2}$. We tried different ways of determining these parameters and obtained the best fit if $N_{\max }, \alpha$ and $v_{a}$ are treated as global parameters (temperature independent) and the equilibrium constants $K_{1}$ and $K_{2}$ are considered as temperature-dependent nested parameters. The constants $C_{1}, E_{1}, C_{2}$, and $E_{2}$ were then determined from straight-line fits of $\ln \left(K_{i} \sqrt{T}\right)$ plotted against $1 / T$. Table 2 lists these empirically determined constants for the double-Langmuir fits. Figure 1a compares the fits against the experimental data for excess $\mathrm{H}_{2}$ uptake and shows an excellent match for 
temperatures down to $40 \mathrm{~K}$, if the $\mathrm{H}_{2}$ density is calculated using the Benedict-Webb-Rubin (BWR) equation of state for non-ideal gases as implemented in REFPROP [20].

To further reduce the number of empirical constants, we followed the same procedure to fit the MOF-5 uptake data with the single Langmuir-equation $(\alpha=1)$. Figure $1 \mathrm{~b}$ shows an equally good fit for temperatures between 50 and $298 \mathrm{~K}$. The coefficient of determination $\mathrm{R}^{2}$ for the doubleLangmuir fit at $77 \mathrm{~K}$ was 0.99 and decreased only slightly to 0.93 for the single Langmuir fit. The fit is not shown for temperatures below $50 \mathrm{~K}$ but it is not as good. Table 2 includes the optimum choice of the empirical parameters for the single-Langmuir equation.

The single-Langmuir equation is very appealing for reverse engineering as it only has four parameters $\left(N_{\max }, v_{a}, C_{1}\right.$, and $\left.E_{1}\right)$, three of which can be related to measurable physical material properties. $N_{\max }$ may be regarded as the sorption capacity $\left(\mathrm{g}-\mathrm{H}_{2} \cdot \mathrm{kg}^{-1}\right)$ of the sorbent, i.e., the maximum absolute uptake if all the active sites are occupied with $\mathrm{H}_{2}$. For a perfect gas, Eq. (3) can be rearranged to show that the differential enthalpy of adsorption $\left(\Delta \bar{h}_{a}\right)$ and molar integral entropy at saturation $\left(\Delta s_{a}\right)$ are related to $E_{1}$ and $C_{1}$ as follows $\left(P_{0}=1\right.$ bar) [21].

$$
\begin{aligned}
& K_{1}=\frac{C_{1}}{\sqrt{T}} e^{\frac{E_{1}}{R T}}=\left(\frac{1}{P_{0}}\right) e^{\Delta s_{a} / R} e^{-\Delta h_{a} / R T} \\
& \Delta \bar{h}_{a}=-\left(E_{1}+\frac{1}{2} R T\right) \\
& \frac{\Delta s_{a}}{R}=\ln \left(\frac{C_{1}}{\sqrt{T}}\right)+\frac{1}{2}
\end{aligned}
$$

For most materials, including MOF-5, $\Delta s_{a} / R$ may be approximated as being equal to 8 since $\Delta s_{a}$ is determined primarily by the entropy of $\mathrm{H}_{2}$ but the fit is better if the weak temperature dependence indicated in Eq. (6) is included. 


\subsection{Thermodynamics of Adsorption}

Following Myers [22], we use solution thermodynamics for adsorption in microporous adsorbents. For a single component system, the molar excess enthalpy $\left(h_{e}\right)$ may be defined with respect to the enthalpy $\left(h_{o}\right)$ of the perfect-gas reference state at the same temperature.

$$
h_{e}=\frac{H_{e}}{N_{e}}=h_{0}+\frac{1}{N_{e}} \int_{0}^{N_{e}} \Delta \bar{h}_{e} d N_{e}
$$

In Eq. (7), the integration has to be done at constant temperature and $\Delta \bar{h}_{e}$ is the differential excess enthalpy that is related to fugacity $(f)$.

$$
\Delta \bar{h}_{e}=-R T^{2}\left[\frac{\partial \ln f}{\partial T}\right]_{N_{e}}
$$

Note that the isosteric heat of adsorption $\left(q_{e}\right)$ that is more frequently quoted in literature simply equals the negative of $\Delta \bar{h}_{e}$. Equations (7) and (8) can be solved numerically to determine $\Delta \bar{h}_{e}$ and $h_{e}$ once excess uptake $N_{e}$ is measured as function of pressure and temperature. For reverse engineering purpose, it is convenient, but not necessary, to approximate Eq. (8) as

$$
\Delta \bar{h}_{e} \approx-\frac{T}{\rho_{g}}\left[\frac{\partial P}{\partial T}\right]_{N_{e}}=-z R T^{2}\left[\frac{\partial \ln P}{\partial T}\right]_{N_{e}}
$$

With the above approximation, an analytical expression can be obtained for the differential excess enthalpy.

$$
\Delta \bar{h}_{e}=-z\left(E_{1}+\frac{1}{2} R T\right)+\left(\frac{v_{a} \rho_{g} N_{\max }}{N_{e}-N_{\max }+2 v_{a} \rho_{g} N_{\max }}\right) z\left(E_{1}-\frac{1}{2} R T\right)
$$

Equation (7) can be integrated analytically if Eq. (10) is substituted for $\Delta \bar{h}_{e}$ and $\rho_{g}$ is replaced

by $\left\langle\rho_{g}\right\rangle$, the average gas density over the range of excess uptake from 0 to $N_{e}$ at temperature $T$. Integration leads to the following equation for the molar excess enthalpy. 
$h_{e}=h_{0}-<z>\left(E_{1}+\frac{1}{2} R T\right)\left[1-\left(\frac{v_{a}\left\langle\rho_{g}\right\rangle N_{\text {max }}}{N_{e}}\right) \ln \left(\frac{N_{e}-N_{\text {max }}+2 v_{a}\left\langle\rho_{g}\right\rangle N_{\max }}{2 v_{a}\left\langle\rho_{g}\right\rangle N_{\text {max }}-N_{\max }}\right)\right]$

Following the same procedure, one can also derive an equation for the differential absolute enthalpy $\left(\Delta \bar{h}_{a}\right)$ and the molar absolute enthalpy $\left(h_{a}\right)$ as equivalent to Eqs. (10) and (11) for the excess enthalpy functions.

$$
\begin{aligned}
& \Delta \bar{h}_{a} \approx-z\left(E_{1}+\frac{1}{2} R T\right) \\
& h_{a}=h_{0}-\langle z\rangle\left(E_{1}+\frac{1}{2} R T\right)
\end{aligned}
$$

For illustrative purposes, Fig. 2 presents $\Delta \bar{h}_{e}$ and $h_{e}$ for $\mathrm{H}_{2}$ adsorption on MOF-5 as calculated by numerically solving Eqs. (7) and (8) and using the empirical constants listed in Table 2. Figure 2a shows that $\Delta \bar{h}_{e}$ is higher at higher temperatures, decreases with increase in uptake at low temperatures and for small $N_{e}$, and is singular at the inflection point where the isothermal $N_{e}$ vs. $P$ curve has a peak (see Fig. 1a). Only the data to the left of this singularity are included in Fig. 2a. As noted by Myers [22], the molar excess enthalpy $\left(h_{e}\right)$ in Fig. 2b, however, is continuous since the singularity in $\Delta \bar{h}_{e}$ is integrable.

Included in Fig. 2 as symbols are $\Delta \bar{h}_{e}$ and $h_{e}$ estimated from Eqs. (10) and (11). We observe that Eq. (10) is a good approximation to $\Delta \bar{h}_{e}$ under most conditions, but $h_{e}$ calculated from Eq. (11) deviates from the exact solution of Eq. (7) for high pressures and low temperatures, under which conditions, the fugacity factor is not unity.

\subsection{Dynamic Model}

As in previous work [15], the dynamic model is formulated from the differential equations that describe the mass and energy balances for a control volume that includes the contents of the 
storage tank inside the vacuum insulation. Unlike the previous work, the $\mathrm{H}_{2}$ mass balance is written in terms of the excess uptake $\left(N_{e}\right)$ and the energy equation is written formally using the molar excess enthalpy $\left(h_{e}\right)$ defined in Eq. (7).

$$
\begin{aligned}
& \frac{d m_{H_{2}}}{d t}=\dot{m}_{H_{2}}^{\text {in }}-\dot{m}_{H_{2}}^{\text {out }} \\
& \frac{d}{d t}\left[m_{S} u_{S}+m_{H_{2}} u_{H_{2}}\right]=\dot{m}_{H_{2}}^{\text {in }} h_{\text {in }}-\dot{m}_{H_{2}}^{\text {out }} h_{g}+\dot{Q}_{\text {in }}
\end{aligned}
$$

where $m_{\mathrm{H}_{2}}$ is the total mass and $m_{\mathrm{H}_{2}} u_{\mathrm{H}_{2}}$ is the total internal energy of stored $\mathrm{H}_{2}$.

$$
\begin{aligned}
& m_{H_{2}}=m_{e}+m_{g} \\
& m_{e}=m_{s} N_{e} \\
& m_{g}=\varepsilon_{v} V_{m} \rho_{g} \\
& m_{H_{2}} u_{H_{2}}=m_{e} h_{e}+m_{g} u_{g}=m_{s} N_{e} h_{e}+m_{g} h_{g}-\varepsilon_{v} V_{m} P
\end{aligned}
$$

Here $V_{m}$ is the volume of the storage media and $\varepsilon_{v}$ is the void volume fraction. We can follow the procedure outlined in Ref. [15] to arrive at the following equations for temporal variations in pressure and temperature.

$$
\begin{aligned}
& \left\{m_{s}\left(\frac{\partial N_{e}}{\partial P}\right)_{T}+\varepsilon_{v} V_{m}\left(\frac{\partial \rho_{g}}{\partial P}\right)_{T}\right\} \frac{d P}{d t}+\left\{m_{s}\left(\frac{\partial N_{e}}{\partial T}\right)_{P}+\varepsilon_{v} V_{m}\left(\frac{\partial \rho_{g}}{\partial T}\right)_{P}\right\} \frac{d T}{d t}=\dot{m}_{H_{2}}^{\text {in }}-\dot{m}_{H_{2}}^{\text {out }} \\
& \left\{m_{s}\left[N_{e}\left(\frac{\partial h_{e}}{\partial P}\right)_{T}+h_{e}\left(\frac{\partial N_{e}}{\partial P}\right)_{T}\right]+\varepsilon_{v} V_{m}\left[\rho_{g}\left(\frac{\partial h_{g}}{\partial P}\right)_{T}+h_{g}\left(\frac{\partial \rho_{g}}{\partial P}\right)_{T}\right]-\varepsilon_{v} V_{m}\right\} \frac{d P}{d t} \\
& +\left\{m_{S} C_{S}+m_{s}\left[N_{e}\left(\frac{\partial h_{e}}{\partial T}\right)_{P}+h_{e}\left(\frac{\partial N_{e}}{\partial T}\right)_{P}\right]+\varepsilon_{v} V_{m}\left[\rho_{g}\left(\frac{\partial h_{g}}{\partial T}\right)_{P}+h_{g}\left(\frac{\partial \rho_{g}}{\partial T}\right)_{P}\right]\right\} \frac{d T}{d t} \\
& =\dot{m}_{H_{2}}^{\text {in }} h_{\text {in }}-\dot{m}_{H_{2}}^{\text {out }} h_{g}+\dot{Q}_{\text {in }}
\end{aligned}
$$


Equations (20) and (21) can be used to determine the pressure, temperature and $\mathrm{H}_{2}$ distribution in the tank during refueling $\left(\dot{m}_{H_{2}}^{\text {out }}=0\right)$ and discharge $\left(\dot{m}_{H_{2}}^{\text {in }}=0\right)$. The formulation is also applicable to dormancy and boil-off, and can also be modified to account for para-to-ortho conversion that occurs with liquid $\mathrm{H}_{2}$ refueling [23].

\subsection{Method of Solution}

As in previous work [15], we used the Adams-Bashford-Molton method in the Gear package [24] to integrate the ordinary differential equations (ODE), Eqs (20)-(21); the Benedict-WebbRubin equation of state in REFPROP [20] to determine the thermodynamic properties of hydrogen; and the Debye model recommended by Barron [25] to estimate the specific heat of the vessel's structural components at low temperatures. The main challenge in this work was to calculate the derivatives $\left(\partial h_{e} / \partial P\right)_{T}$ and $\left(\partial h_{e} / \partial T\right)_{P}$ inside the ODE solver since $h_{e}$ can only be determined by numerically performing the integration indicated in Eq. (7). The task was simpler and more expedient if the fugacity factor is close to unity so that $h_{e}$ can be approximated by using Eq. (11). Also, it was more convenient to rewrite Eqs. (20) and (21) in terms of the isobaric $(\beta)$ and isothermal ( $\kappa)$ compressibility of $\mathrm{H}_{2}$ as these are calculated directly within REFPROP.

$$
\begin{aligned}
& \left\{m_{s}\left(\frac{\partial N_{e}}{\partial P}\right)_{T}+\varepsilon_{v} \kappa \rho_{g} V_{m}\right\} \frac{d P}{d t}+\left\{m_{s}\left(\frac{\partial N_{e}}{\partial T}\right)_{P}-\varepsilon_{v} \beta \rho_{g} V_{m}\right\} \frac{d T}{d t}=\dot{m}_{H_{2}}^{\text {in }}-\dot{m}_{H_{2}}^{\text {out }} \\
& \left\{m_{s}\left[N_{e}\left(\frac{\partial h_{e}}{\partial P}\right)_{T}+h_{e}\left(\frac{\partial N_{e}}{\partial P}\right)_{T}\right]+\varepsilon_{v} V_{m}\left[-\beta T+\kappa \rho_{g} h_{g}\right]\right\} \frac{d P}{d t} \\
& +\left\{m_{S} C_{S}+m_{s}\left[N_{e}\left(\frac{\partial h_{e}}{\partial T}\right)_{P}+h_{e}\left(\frac{\partial N_{e}}{\partial T}\right)_{P}\right]+\varepsilon_{v} \rho_{g} V_{m}\left[C_{p g}-\beta h_{g}\right]\right\} \frac{d T}{d t} \\
& =\dot{m}_{H_{2}}^{\text {in }} h_{\text {in }}-\dot{m}_{H_{2}}^{\text {out }} h_{g}+\dot{Q}_{\text {in }}
\end{aligned}
$$

Note that the derivatives $\left(\partial N_{e} / \partial P\right)_{T}$ and $\left(\partial N_{e} / \partial T\right)_{P}$ in the above equations can be evaluated analytically for the single-Langmuir isothem as 


$$
\begin{aligned}
& \left(\frac{\partial N_{e}}{\partial P}\right)_{T}=N_{e}\left[-\frac{\kappa v_{a} \rho_{g}}{1-v_{a} \rho_{g}}+\frac{1}{P\left(1+K_{1} P\right)}\right] \\
& \left(\frac{\partial N_{e}}{\partial T}\right)_{P}=N_{e}\left[\frac{\beta v_{a} \rho_{g}}{1-v_{a} \rho_{g}}-\left(\frac{1}{1+K_{1} P}\right) \frac{1}{T}\left(\frac{1}{2}+\frac{E_{1}}{R T}\right)\right]
\end{aligned}
$$

\section{Results and Discussion}

Figure 3 is a schematic of the onboard storage system adapted from our earlier work [15]. The storage vessel is a carbon-fiber-wound Type 3 tank that is thermally insulated with multi-layer vacuum super insulation (MLVSI) encased in a 3-mm-thick Al alloy vacuum shell. Unlike the previous work, the storage medium is in the form of sorbent powder mixed with a thermal conductivity enhancement material, and compacted into discs. The main balance-of-plant components include the pressure regulator, heat exchanger, pressure transducers, pressure relief devices, rupture discs, valves and tubing. During charging, the tank is refueled with cold hydrogen and the heat of adsorption is removed by circulating an off-board coolant through the tank internal heat exchanger tubes. During discharge, the heat of desorption and any temperature swing in the sorbent bed is provided by recirculating the enclosed refrigerant through a small external heat exchanger. The hydrogen withdrawn from the tank for use by the fuel cell is preheated using the fuel cell waste heat before being fed to the fuel cell stack. As in previous work, the storage medium and system are designed to provide $5.6 \mathrm{~kg}$ of usable $\mathrm{H}_{2}$ at 5-bar minimum delivery pressure, and they can be refueled at an average rate of $1.5 \mathrm{~kg} \cdot \mathrm{min}^{-1}$.

\subsection{Off-board Refueling Interface}

Figure 4 shows the off-board hydrogen production pathway including the refueling interface considered in determining the well-to-tank (WTT) efficiency. As summarized in Table 3, the pathway consists of a central plant where hydrogen is produced by steam reforming of natural gas (SMR), compressed, and transmitted via pipeline to the refueling station. More complete 
details are available elsewhere [26, 27]; here, we emphasize only the novel part of the analysis related to off-board refrigeration. At the forecourt, hydrogen received from the pipeline is first compressed for bulk storage. Hydrogen that is withdrawn from bulk storage is cooled by a cryogenic system, stored in insulated Type I tubes at 135\% of the onboard storage pressure, and dispensed using a cascade refueling system. As shown in Fig. 4, the cryogen is also circulated through the onboard storage tank to remove the heat of adsorption that is released during refueling.

Coefficient of performance (COP), defined as the ratio of the cooling load to the electrical energy consumed, is a metric commonly used to characterize the efficiency of refrigeration cycles. Thermodynamically, the lower the refrigeration temperature the smaller is the COP. In practice, $\mathrm{COP}$ also depends on the refrigerant, refrigeration cycle, and the performance of the system components such as the compressors, expanders and heat exchangers. Table 4 summarizes the performance of some industrial refrigeration units extracted from the available literature data for representative systems ranging from industrial $\mathrm{H}_{2}$ liquefaction at $20 \mathrm{~K}$ to commercial refrigerated storage at $230-275 \mathrm{~K}$. The existing hydrogen liquefaction plants have 0.5-40 tons per day (tpd) capacity; many use modified Claude cycle (rather than the simpler Brayton cycle) and nitrogen as pre-coolant since the triple-point temperature of $\mathrm{H}_{2}$ is below its maximum inversion temperature $[25,28]$. Liquid nitrogen is produced commercially from cryogenic distillation of liquefied air or from the liquefaction of pure nitrogen derived from air using pressure swing adsorption $[29,30]$. Liquefied natural gas (LNG) is produced commercially using mixed-refrigerant (MR) or cascade cycles at large plants (>7500 tpd capacity) or reverse Brayton nitrogen cycle (or $\mathrm{N}_{2}$ expansion cycle) at small-scale LNG plants [31, 32]. Commercial 
very low temperature (VLT) refrigeration units using vapor compression cycles and non-ozone depleting CFC-free refrigerants are available in several $\mathrm{kW}$ to MW cooling capacity [33, 34].

Figure 5a is a graphical compilation of the performance of the data in Table 4 showing that COP varies from $\sim 0.01$ for $\mathrm{H}_{2}$ liquefaction at $20 \mathrm{~K}$ to $3-5$ for VLT applications at $275 \mathrm{~K}$. Figure $5 \mathrm{~b}$ further segregates and correlates the COP data for small applications with $<5 \mathrm{~kW}$ capacity, large central plants with $>200 \mathrm{~kW}$ capacity, and $50-60 \mathrm{~kW}$ intermediate plants appropriate for 1000$\mathrm{kg} \cdot \mathrm{d}^{-1}$ distributed $\mathrm{H}_{2}$ generation and refueling stations.

We used the COP correlation for distributed plants to determine the WTT efficiency of the $\mathrm{H}_{2}$ production and delivery pathway in Table 2 for different refrigeration temperatures and cooling duty. The results are presented in Fig. 6 as allowable cooling duty (MJ.kg- $\mathrm{H}_{2}^{-1}$ ) for specified WTT efficiency, refrigeration temperature and storage pressure. The allowable cooling duty is clearly seen to be very sensitive to the WTT efficiency and the refrigeration temperature. For example, there is nearly four-fold decrease in the allowable cooling duty (from 5.8 to $1.0 \mathrm{MJ} . \mathrm{kg}$ $\mathrm{H}_{2}^{-1}$ ) at the liquid $\mathrm{N}_{2}$ temperature if the WTT efficiency is raised from $40 \%$ to $60 \%$. On the other hand, there is a three-fold increase in the allowable cooling duty if the WTT efficiency is 50\% and the refrigeration temperature is raised from $77 \mathrm{~K}$ to $150 \mathrm{~K}$.

\subsection{Advanced Sorbents}

Need for advanced sorbents with high intrinsic capacity $\left(N_{\max }\right)$ and differential enthalpy of adsorption (characterized by the Langmuir parameter $E_{l}$ ) can be ascertained by rewriting Eq. (1) for single-Langmuir isotherm in terms of $\mathrm{H}_{2}$ coverage $(\theta)$.

$$
\begin{aligned}
& N_{a}=N_{\text {max }} \theta \\
& \theta=\frac{K_{1} P}{1+K_{1} P}
\end{aligned}
$$


Assuming that the integral entropy at saturation (i.e., the Langmuir parameter $C_{l}$ is fixed) is unlikely to deviate much from $66.5 \mathrm{~J} \cdot \mathrm{mol}^{-1} \cdot \mathrm{K}^{-1}$, Fig. 7a presents coverage as a function of $E_{l}$ and storage temperature at 100 bar, near the upper limit of storage pressures being considered for sorbent systems. Ideally, the operating pressure and temperature should be selected such that the coverage is close to unity, ensuring that all the active sites are utilized for $\mathrm{H}_{2}$ storage. Figure $7 \mathrm{a}$ indicates that the ideal storage temperature at 100-bar storage pressure is a function of $\Delta \bar{h}_{a}$. A storage temperature of $50 \mathrm{~K}$ is required for a low- $\Delta \bar{h}_{a}$ material, such as MOF-5 with $E_{1}=3.1$ $\mathrm{kJ} . \mathrm{mol}^{-1}$, for coverage to reach unity. Storage temperatures below $150 \mathrm{~K}$ are not necessary for hypothetical sorbents with $E_{1}>7.5 \mathrm{~kJ} \mathrm{~mol}^{-1}$. Sorbents with $E_{l}>10 \mathrm{~kJ} \cdot \mathrm{mol}^{-1}$ would be needed for efficacious $\mathrm{H}_{2}$ storage at near room temperature.

On reaching unity coverage at the appropriate temperatures, the storage capacity becomes limited by $N_{\max }$. For a given material and synthesis method, $N_{\max }$ is generally proportional to the specific surface area of the sorbent $\left(\mathrm{m}^{2} \cdot \mathrm{g}^{-1}\right)$.

Figure $7 \mathrm{~b}$ presents the same results as Fig. $7 \mathrm{a}$ but at 5-bar minimum delivery pressure. The difference in coverage in Figs $7 \mathrm{a}$ and $7 \mathrm{~b}$ for the same $E_{1}$ and temperature is the usable isothermal storage capacity with a pressure swing from 100 bar to 5 bar. Over the temperature range where $\theta \approx 1$, this usable capacity is $<20 \%$ for a near-term material with an $E_{l}$ of $3.1 \mathrm{~kJ}^{-\mathrm{mol}^{-1}}$ (at $50 \mathrm{~K}$ ) and $<40 \%$ for an advanced material with an $E_{l}$ of $7.5 \mathrm{~kJ}^{-\mathrm{mol}^{-1}}$ (at $150 \mathrm{~K}$ ). The usable isothermal capacity can be increased by superimposing a temperature swing on top of the pressure swing. If a $90 \%$ usable capacity is desired, this temperature swing must be $\sim 50 \mathrm{~K}$ for the material with $E_{l}$ of $3.1 \mathrm{~kJ} \cdot \mathrm{mol}^{-1}$ and $\sim 50 \mathrm{~K}$ for the material with $E_{l}$ of $7.5 \mathrm{~kJ} \mathrm{~mol}^{-1}$. 
In summary, development of a compact sorbent-based $\mathrm{H}_{2}$ storage system requires an advanced micro-porous adsorbent with high specific surface area (active sites) and $E_{1}>5 \mathrm{~kJ}_{\mathrm{mol}}{ }^{-1}$ as well as low storage temperatures and temperature swings sufficient for $>90 \%$ usable capacity.

\subsection{Medium Thermal Conductivity}

In powder form, metal hydrides and adsorbents have low bulk density and poor thermal conductivity. Meeting the stringent volumetric target requires that the powders be mechanically compacted and consolidated to form pellets and disks. Attention must be paid to allow for the volumetric changes that occur as the material expands upon hydriding and also to the contact resistance between the compact and heat transfer surfaces. The compacts also must possess sufficient permeability for acceptably uniform hydrogen flow during rapid charging so that the sorption kinetics is not greatly impaired.

Many methods have been investigated to augment heat transfer in powder beds, including the use of metal foams, wires and fins $[35,36]$. Densified compacts with high conductivity materials, such as aluminum powder and expanded natural graphite (ENG), as additives appear particularly promising. Sanchez et al. [37] have shown that the measured effective thermal conductivity $\left(\lambda_{\text {eff }}\right)$ of these compacts can be correlated by a simple model with parallel thermal resistances of metal hydride and the enhanced heat transfer additive.

$$
\lambda_{e f f}=\varepsilon_{s} \lambda_{s}+\varepsilon_{E G} \lambda_{E G}
$$

In the above equation, $\varepsilon$ is the material fill factor and it can be represented in terms of the mass fractions $(Y)$, sorbent $\left(\rho_{s}\right)$ and ENG $\left(\rho_{E G}\right)$ material densities, and the bulk density $\left(\rho_{b}\right)$ of the bed composed of these compacts.

$\varepsilon_{s}=Y_{s}\left(\frac{\rho_{b}}{\rho_{s}}\right)$ 


$$
\begin{aligned}
& \varepsilon_{E G}=Y_{E G}\left(\frac{\rho_{b}}{\rho_{E G}}\right) \\
& \varepsilon=\varepsilon_{s}+\varepsilon_{E G}
\end{aligned}
$$

Liu et al. [38] investigated the transport properties of MOF-5 composites compacted to $300-$ $700 \mathrm{~kg} \cdot \mathrm{m}^{-3}$ density and mixed with $1-10 \mathrm{wt} \%$ of ENG. They found that compacting MOF-5 pellets from 300 to $700 \mathrm{~kg} \cdot \mathrm{m}^{-3}$ can more than double the thermal conductivity and that addition of $10 \mathrm{wt} \%$ ENG to MOF-5 pellets of $500 \mathrm{~kg} \cdot \mathrm{m}^{-3}$ density can result in four-fold increase in the thermal conductivity.

We have used Eqs. (24) - (27), originally developed for metal hydride composites, to correlate the Liu data for neat MOF-5 and MOF-5/ENG composites. Figure 8 displays an optimum $\lambda_{\text {eff }}$ correlation with $\lambda_{s}=0.22 \mathrm{~W} \cdot \mathrm{m}^{-1} \cdot \mathrm{K}^{-1}, \lambda_{E G}=21.2 \mathrm{~W} \cdot \mathrm{m}^{-1} \cdot \mathrm{K}^{-1}, \rho_{s}=1465 \mathrm{~kg} \cdot \mathrm{m}^{-3}$, and $\rho_{E G}=1873$

$\mathrm{kg} . \mathrm{m}^{-3}$. The fits are quite good for neat MOF-5 and MOF-5 mixed with 1 wt\% ENG, acceptable for $10 \mathrm{wt} \% \mathrm{ENG}$, and only marginal for $5 \mathrm{wt} \%$ ENG. It also indicates that densification above $400 \mathrm{~kg} \cdot \mathrm{m}^{-3}$ and $>5 \mathrm{wt} \%$ ENG are needed if the bed is to have thermal conductivity higher than $0.4 \mathrm{~W} \cdot \mathrm{m}^{-1} \cdot \mathrm{K}^{-1}$.

\subsection{Containment Tank}

Type 3 tanks may be preferred for containing sorbents if the storage temperature is below the glass transition temperature or the ductile-to-brittle temperature of the high-density polyethylene generally used as the liner material in Type-4 tanks [39]. Type 3 tanks consist of an inner aluminium liner that is highly resistant to $\mathrm{H}_{2}$, and an outer layer of wound high strength carbon fiber-resin (CF) composite designed to withstand $225 \%$ of the nominal storage pressure. Table 5 summarizes the mechanical properties of the most-common in use high-strength and highmodulus T700S fiber and the fiber-resin composite with $60 \%$ T700S fiber by volume [40]. Prior 
to formal finite-element analysis using codes such as ABAQUS [41, 42], the tank geometry, optimal dome shape, winding angle, and preliminary helical- and hoop-layer thicknesses of the CF overwrap are generally determined by a netting analysis. A geodesic winding design for the dome, in which all fibers are uniformly stressed and display no shearing or bending stiffness, has a minimum mass of the CF composite for a given cylinder diameter and storage pressure [43-45]. Typically, the helical thickness is about half the hoop thickness in the cylinder section, and increases in the dome. Type 3 pressure vessels that are subjected to fluctuating pressure and temperature are auto-frettaged to extend the fatigue life of the metal liners [46]. The United Nations Global Technical Regulation on Hydrogen and Fuel Cell Vehicles requires a fatigue life of at least 5500 pressure cycles at $125 \%$ of the nominal pressure [47].

Figure 9 shows the weight and volume of 110-L Type-3 containment tanks as a function of storage pressure for designs in which the CF overwrap bears $85-90 \%$ of the pressure load with the balance being absorbed by the liner. The amount of CF needed is directly proportional to the storage pressure. For storage pressures under 50 bar, the liner thickness is held constant at a minimum value, but it increases with increasing pressures above 50 bar because the liner is sized to bear a fixed percentage of the pressure load. At the highest analyzed storage pressure of 150 atm, the containment tank accounts for $\sim 23 \%$ of the weight of an on-board storage system that stores $5.6 \mathrm{~kg}$ usable $\mathrm{H}_{2}$ and has $5.5 \%$ gravimetric capacity. For comparison, the containment tank for a 700-bar compressed hydrogen storage system accounts for $\sim 70 \%$ of the total system weight [48].

\subsection{Reverse Engineering Study}

We have used the dynamic model in a reverse engineering study to determine the material properties that would be needed to meet the automotive storage system capacity and performance 
targets. Table 6 lists the reference values and ranges of study parameters. We assume that the following are specified: sorbent properties $v_{a}$ and $C_{l}$; minimum delivery pressure; $\mathrm{H}_{2}$ refueling rate and minimum full flow rate; heat transfer tube parameters (aluminium tube diameter, tube wall thickness); weight and volume of the balance-of-plant (BOP) components (pumps, valves, piping, etc.); and $\mathrm{H}_{2}$ collection and distribution system (five stainless-steel sintered metal tubes). The following are the target performance parameters to be determined from the reverse engineering analysis: 1) material sorption capacity defined as the peak excess uptake at the liquid $\mathrm{N}_{2}$ temperature $\left(N_{e}^{\max }(77 K)\right) ; 2$ ) differential enthalpy of adsorption $\left.\left(E_{1}\right) ; 3\right)$ bulk density of sorbent/ENG composite $\left(\rho_{b}\right)$; 4) storage medium thermal conductivity $\left(\lambda_{\text {eff }}\right)$ and ENG weight fraction $\left(Y_{E G}\right)$; 5) storage pressure and temperature; 6) coolant temperature; 7) number of heat transfer tubes; 8) liner thickness; 9) CF composite thickness; 10) vessel diameter and length, and 11) insulation thickness.

The reverse engineering analysis is conducted subject to the following constraints that must be satisfied: 1) amount of usable $\left.\mathrm{H}_{2}(5.6 \mathrm{~kg}) ; 2\right)$ system gravimetric capacity $(5.5 \mathrm{wt} \%)$; 3) system volumetric capacity $\left(40\right.$ g. $\left.\left.\mathrm{L}^{-1}\right) ; 4\right)$ minimum full flow rate of $\mathrm{H}_{2}\left(1.6 \mathrm{~g} . \mathrm{s}^{-1}\right.$ for an $80-\mathrm{kW}$ fuel cell power system); 5) refueling rate (1.5 $\left.\mathrm{kg} \cdot \mathrm{min}^{-1}\right)$; 6) well-to-tank efficiency $(55 \%)$; 7) usable fraction of total $\mathrm{H}_{2}$ storage capacity (95\%, a study parameter); 8) SAE code for liner fatigue (5500 cycles); 9) SAE code for burst safety factor (2.25); 10) vessel aspect ratio (study parameter); and 11) heat gain from ambient $(5 \mathrm{~W})$.

We assume $100 \%$ onboard efficiency so that the well-to-tank efficiency is the same as the wellto-poweplant efficiency. In the reverse engineering study, we choose a well-to-tank efficiency of $55 \%$ in lieu of the DOE well-to-powerplant target of $60 \%$ because meeting the higher and more restrictive efficiency target would also require improvement in hydrogen production which is 
beyond the scope of this study. Additionally, the 55\% well-to-tank efficiency is in line with the 54-55\% efficiency attained for compressed hydrogen storage at 700 bar [48].

There is not a one-to-one correspondence between the performance parameters and the constraints. For example, bulk density affects both the volumetric capacity and the thermal conductivity, and, hence the refueling rate. A multidimensional non-linear equation solver is needed and one based on the steepest descent method with quasi-Newton update has been found to be particularly suitable. The challenge was to embed, within the iteration loop of the equation solver, the ODE solution algorithm discussed in Section 2.3 for determining the temperature profile, uptake and refueling time.

Not all the material and operating parameters were varied simultaneously inside the equation solver. Instead, a single-variable parametric study was performed to evaluate the effects of coolant temperature $\left(T_{f}\right)$, storage temperature $(T)$, storage pressure, ENG weight fraction $\left(Y_{E G}\right)$, and differential enthalpy of adsorption (as characterized by $E_{1}$ ). However, unless noted otherwise, the constraints listed above were imposed even in the parametric study.

Table 7 lists the concurrent material targets and operating temperatures determined from the study for $E_{l}=5 \mathrm{~kJ} \cdot \mathrm{mol}^{-1}, 100$ bar storage pressure, $135 \mathrm{~K}$ off-board coolant temperature, $155 \mathrm{~K}$ storage temperature, and 20-wt\% ENG. These are briefly discussed below.

- We calculate that a sorbent with $E_{1}=5 \mathrm{~kJ} \cdot \mathrm{mol}^{-1}$ must have $N_{e}^{\max }(77 K)$ of $190 \mathrm{~g}-\mathrm{H}_{2} \cdot \mathrm{kg}^{-1}$ for the system to have $5.5 \mathrm{wt} \%$ gravimetric capacity. Such a sorbent will have $120 \mathrm{~g}-\mathrm{H}_{2} \cdot \mathrm{kg}^{-1}$ excess capacity at $155 \mathrm{~K}$ storage temperature and 100 bar storage pressure.

- The model indicates that the sorbent must be compacted to $420 \mathrm{~kg} \cdot \mathrm{m}^{-3}$ bulk density to satisfy the 40 g. $\mathrm{L}^{-1}$ system volumetric capacity target. According to Eq. (24), when mixed with 20 $\mathrm{wt} \% \mathrm{ENG}$, this sorbent/ENG composite has a thermal conductivity of $1 \mathrm{~W} \cdot \mathrm{m}^{-1} \cdot \mathrm{K}^{-1}$. 
- We calculate that a $60 \mathrm{~K}$ temperature swing has to be imposed for $95 \%$ usable $\mathrm{H}_{2}$ while the bed is depressurized from 100 bar storage pressure to the target 5 bar minimum delivery pressure.

- With a $20 \mathrm{~K}$ terminal temperature differential between the coolant and bed during refueling, the analysis indicates that the off-board coolant temperature cannot be higher than $135 \mathrm{~K}$ if a WTT efficiency $>55 \%$ is desired.

- A total of $112 \mathrm{U}$ tubes are needed to cool the bed and remove the heat of sorption and the Joule-Thomson heating effect sufficiently rapidly to achieve a $1.5 \mathrm{~kg} \cdot \mathrm{min}^{-1} \mathrm{H}_{2}$ refueling rate. Figure 10 presents the weight and volume distributions of the reference system components grouped as medium (sorbent, $48 \mathrm{~kg}, 95.8 \mathrm{~L}$ ), heat transfer subsystem (tubes, ENG, $17.3 \mathrm{~kg}, 14.1$ L), structure (liner, CF, plug, $16 \mathrm{~kg}, 7.2 \mathrm{~L}$ ), insulation (MLVSI, supports, $0.8 \mathrm{~kg}, 12.5 \mathrm{~L}$ ), shell $(8.6 \mathrm{~kg}, 3.2 \mathrm{~L})$, and miscellaneous (ex-vessel, $11.2 \mathrm{~kg}, 7 \mathrm{~L})$. The medium accounts for $\sim 47 \%$ of the system weight and $\sim 69 \%$ of the system volume. Nearly $17 \%$ of the system weight and $10 \%$ of the system volume are in the heat transfer subsystem. Vacuum insulation contributes $\sim 9 \%$ to the system volume. Even with Type 3 structure, $\sim 16 \%$ of the system weight is in containment tank; the containment tank would be even heavier if Type 1 had to be used for ease of manufacturing and assembly. Similarly, the shell accounts for $\sim 8 \%$ of the system weight and would be even heavier if it was made of cheaper carbon steel rather than aluminum.

\subsection{Refueling Dynamics}

Figure 11 presents the simulation results for refueling the tank in the reference case discussed in Section 3.5. The initial conditions correspond to a tank fully discharged to 5 bar and $215 \mathrm{~K}$ so that $N_{e}=6.1 \mathrm{~g}-\mathrm{H}_{2} \cdot \mathrm{kg}^{-1}$. We consider that the tank is refuelled with $\mathrm{H}_{2}$ pre-cooled to $145 \mathrm{~K}$ and the coolant is circulated through the heat exchanger tubes at $135 \mathrm{~K}$. The refueling event consists 
of two phases. In the first phase, the tank pressure rapidly reaches 100 bar and the tank temperature rises because of the PV work and the heat released by sorption. Assuming that the sorption kinetics is fast, the duration of this phase can be short and is only limited by the volumetric flow rate setting of the refueling nozzle. This phase can be regarded as nearly adiabatic since only small amount of heat can be removed in short duration. The total amount of $\mathrm{H}_{2}$ fed to the tank in the adiabatic phase $\left(m_{H_{2}}^{i n}\right), \mathrm{H}_{2}$ disposition $\left(m_{g}\right.$ and $\left.N_{e}\right)$, and the final temperature can be determined from the following difference equations.

$$
\Delta\left[m_{e}+m_{g}\right]=m_{H_{2}}^{i n}
$$

$\Delta\left[m_{S} u_{S}+m_{s} N_{e} h_{e}+m_{g} h_{g}-\varepsilon_{v} V_{m} P\right]=m_{H_{2}}^{i n} h_{\text {in }}$

Table 8 lists the changes in $T, N_{e}, \rho_{g}$ and $\rho_{H_{2}}\left(\varepsilon_{v} \rho_{g}+\rho_{s} N_{e}\right)$ during the adiabatic phase of refueling.

Further $\mathrm{H}_{2}$ refueling occurs at constant pressure during the second phase and requires heat transfer. Figure 11 presents the total amount of heat that is removed and the decrease in temperature for excess uptake to reach $116.6 \mathrm{~g}-\mathrm{H}_{2} \cdot \mathrm{kg}^{-1}$ as is required for $5.6 \mathrm{~kg}$ of $\mathrm{H}_{2}$ refueled. Nearly $75 \%$ of the cooling load is due to the heat of adsorption and $<20 \%$ is due to the sensible cooling corresponding to the $60 \mathrm{~K}$ temperature swing. The PV work shown in Fig. 11 does not include the PV work during the adiabatic portion of refueling.

The total cooling load is $4.2 \mathrm{MJ} \cdot \mathrm{kg}-\mathrm{H}_{2}{ }^{-1}$, divided almost equally between off-board cooling of $\mathrm{H}_{2}$ (2.2 MJ.kg- $\left.\mathrm{H}_{2}^{-1}\right)$ and on-board heat transfer to the coolant (2 MJ.kg- $\left.\mathrm{H}_{2}^{-1}\right)$; the average in-bed heat transfer rate during refueling is $\sim 55 \mathrm{~kW}$. The instantaneous heat transfer rate in Eq. (15) was determined by considering a cylindrical unit cell around a heat exchanger tube of length $l_{x}$, inner diameter $d_{x}$, outer diameter $d_{f}$, and thermal conductivity $k_{x}$. The outer diameter $d_{m}$ of the unit cell was calculated such that the cell volume equals the storage volume $\left(V_{s t}\right)$ divided by the number 
of tubes $\left(n_{x}\right)$. The heat transfer rate was estimated by considering thermal resistances due to convection $\left(R_{f}\right)$, conduction across the tube thickness $\left(R_{x}\right)$, contact resistance $\left(R_{i}\right)$, and conduction across the bed $\left(R_{m}\right)$.

$\dot{Q}_{i n}=\frac{n_{x} \gamma\left(T_{f}-T\right)}{R_{t}}$

$d_{m}=\left(\frac{V_{s t}}{\pi n_{x} l_{x} / 4}\right)^{1 / 2}$

$R_{f}=\frac{1}{\left(\pi d_{f} l_{x}\right) h_{f}}$

$R_{x}=\frac{\ln \left(d_{x} / d_{f}\right)}{2 \pi d_{x} k_{x}}$

$R_{i}=\frac{1}{\left(\pi d_{x} l_{x}\right) h_{i}}$

$R_{m}=\frac{\ln \left(d_{m} / d_{x}\right)}{2 \pi d_{x} k_{m}}$

$R_{t}=R_{f}+R_{x}+R_{i}+R_{m}$

$\gamma=\left[\frac{\left(d_{m} / d_{f}\right)^{2}}{\left(d_{m} / d_{f}\right)^{2}-1}-\frac{1}{2 \ln \left(d_{m} / d_{f}\right)}\right]^{-1}$

As discussed in the earlier work [15], the design and sizing of the in-tank heat exchanger depend on the heat transfer requirement during refueling rather than during discharge since the refueling time (3.7 mins) is much shorter than the typical discharge time (several hours). As a reference, isothermal discharge at $1.6 \mathrm{~g} . \mathrm{s}^{-1}$ minimum full flow rate would incur a thermal heating load of 4 $\mathrm{kW}$, an order of magnitude smaller than $55 \mathrm{~kW}$ average cooling load during refueling. 


\subsection{Sensitivity Study}

A single-variable sensitivity study (Study 1) was conducted to evaluate the effect of coolant temperature on the target material properties. For the purpose of this study, the WTT efficiency constraint was relaxed but all other system performance constraints were maintained. As in Section 3.5, the $\mathrm{H}_{2}$ inlet temperature $\left(\Delta T_{i n}=T_{i n}-T_{f}\right)$ and the storage temperature $\left(\Delta T=T_{f}-T\right)$ were respectively assumed to be $10 \mathrm{~K}$ and $20 \mathrm{~K}$ above the coolant temperature. The results of this sensitivity study are summarized in Fig. 12, which shows that the excess uptake target can be lowered considerably, to $145 \mathrm{~g}-\mathrm{H}_{2} \cdot \mathrm{kg}^{-1}$ from $190 \mathrm{~g}-\mathrm{H}_{2} \cdot \mathrm{kg}^{-1}$, if the off-board coolant temperature is reduced to the liquid $\mathrm{N}_{2}$ temperature. However, the cooling duty increases by $20 \%$, mainly due to higher off-board cooling load. The result of higher cooling load and lower refrigeration temperature is a drastic drop in the WTT efficiency, to $<42 \%$ (see Fig. 6). Figure 12 also indicates that the coolant temperature has to be above $135 \mathrm{~K}$ for $>55 \%$ WTT efficiency but the excess uptake target becomes more stringent.

Another single-variable sensitivity study (Study 2$)$ was conducted in which $\Delta T\left(\Delta T=T-T_{f}\right)$ was varied to explore the effect of storage temperature on the target material properties. As above, the WTT efficiency constraint was relaxed but all other system performance constraints were maintained. Figure 13 indicates that for a fixed coolant temperature, raising the storage temperature by increasing $\Delta T$ results in a lighter heat exchanger, slight improvement in WTT efficiency because of smaller on-board cooling load, but lower uptake. The decrease in the heat exchanger weight does not compensate for the increased medium weight because of reduced gas density and $\mathrm{H}_{2}$ uptake, so that for given $E_{1}, N_{\max }$ has to be raised to satisfy the system gravimetric target. For the conditions of Fig. 13, a $\Delta \mathrm{T}$ of $7 \mathrm{~K}$ is about the optimum in that it leads to the lowest target for $N_{e}^{\max }(77 K)$. Decreasing $\Delta \mathrm{T}$ to $<7 \mathrm{~K}$ is not beneficial because the reduction in 
medium weight due to higher uptake is less than the non-linear increase in heat exchanger weight.

Figure 14 presents results from a sensitivity study (Study 3) on the effect of storage pressure for specified coolant, storage and $\mathrm{H}_{2}$ inlet temperatures. The lower the storage pressure, the lighter the containment (see Fig. 9), but the larger is the temperature swing for 95\% usable capacity (see Fig. 7). Our results indicate that lowering the pressure from 100 to 50 bar is not beneficial, i.e., the uptake target is more stringent because of the reduced gas density and smaller uptake. Similarly, increasing the pressure to 150 bar is not beneficial because of the heavier liner and carbon fiber.

Figure 15 summarizes results from a sensitive study (Study 4) on the effect of bed thermal conductivity (ENG weight ratio) on the uptake target. For the conditions of this study, the combined weight of the ENG and on-board heat exchanger and, therefore, the target uptake, are nearly constant below $Y_{E G}$ of 0.2 . A recent study by Veenstra et al. [49] demonstrated a novel method of enhancing the thermal conductivity of sorbent without just increasing the ENG weight fraction. They reported a factor of twenty increase in thermal conductivity to $4 \mathrm{~W} \cdot \mathrm{m}^{-1} \cdot \mathrm{K}^{-1}$ by using aligned layers of ENG and MOF-5 compared to randomly mixed compacts with same 5wt $\%$ ENG, pressed to the same $0.4 \mathrm{~g} / \mathrm{cm}^{3}$ density. As a first approximation, the following equation may be used to scale the target $N_{e}^{\max }(77 K)$ for the ENG weight fraction (20\% for uniformly mixed compact, $<5 \%$ for layered compact) needed to reach $1 \mathrm{~W} \cdot \mathrm{m}^{-1} \cdot \mathrm{K}^{-1}$ bed effective thermal conductivity.

$N_{e}^{\max }(77 K)=160\left(1+Y_{E G}\right)$ 
Another parametric study (Study 5) was conducted to investigate the effect of the differential enthalpy of adsorption on target uptake for two levels of storage pressures and WTT efficiencies. The important results of this study are presented in Fig. 16 and are briefly summarized below.

- The optimum coolant temperature is higher for sorbents with higher differential enthalpy of adsorption. Meeting storage systems targets at temperatures approaching $200 \mathrm{~K}$, however, requires sorbents with $E_{1}>10 \mathrm{~kJ} \cdot \mathrm{mol}^{-1}$.

- WTT efficiencies $>55 \%$ with target $N_{e}^{\max }(77 \mathrm{~K})<190 \mathrm{~g}-\mathrm{H}_{2} \cdot \mathrm{kg}^{-1}$ are possible with sorbents that have $E_{1}>5 \mathrm{~kJ} \cdot \mathrm{mol}^{-1}$. The optimum coolant temperature for $>55 \%$ WTT efficiency will likely be above $150 \mathrm{~K}$.

- The storage pressure can be reduced to 50 bar for sorbents with $E_{l}>6 \mathrm{~kJ}^{\mathrm{mol}}{ }^{-1}$ and coolant temperature above $135 \mathrm{~K}$. Under optimum conditions for sorbents with $E_{l}>6 \mathrm{~kJ} \cdot \mathrm{mol}^{-1}$, the target $N_{e}^{\max }(77 \mathrm{~K})$ is smaller if the storage pressure is 50 bar than if it is 100 bar.

Finally, Fig. 17 is a tornado plot that graphically summarizes the sensitivity of key performance indices to the operating temperatures and pressure, ENG weight fraction, and the differential heat of adsorption. Besides the target peak excess uptake at $77 \mathrm{~K}$, WTT efficiency and bulk density discussed in considerable detail in this section, the indices include the target excess uptake at the storage pressure and temperature, $N_{e}(P, T)$. Interestingly, under most conditions, the target $N_{e}(P, T)$ varies only over a narrow range centered around $120 \mathrm{~g}-\mathrm{H}_{2} \cdot \mathrm{kg}^{-1}$.

\section{Summary and Conclusions}

A systematic analysis has been carried out to determine the critical properties that sorbents must have to be viable candidates for use in automotive hydrogen storage systems. These material properties are needed for the storage system to achieve the performance targets of $5.5 \mathrm{wt} \%$ gravimetric capacity, 40 g.L $\mathrm{L}^{-1}$ volumetric capacity, 55\% WTT efficiency, 95\% usable $\mathrm{H}_{2}$, and 1.5 
$\mathrm{kg} \cdot \mathrm{min}^{-1}$ refueling rate. The following is a brief summary of the minimum physical, thermodynamic and thermal requirements for the promising sorbents (see also Table 9).

a) $120 \mathrm{~g}-\mathrm{H}_{2} \cdot \mathrm{kg}^{-1}$ excess sorption capacity at $150 \mathrm{~K}$ or higher temperature and 100 bar pressure. An equivalent requirement is $190 \mathrm{~g}-\mathrm{H}_{2} \cdot \mathrm{kg}^{-1}$ peak excess uptake at liquid $\mathrm{N}_{2}$ reference temperature.

b) $5 \mathrm{~kJ} \cdot \mathrm{mol}^{-1}$ differential enthalpy of adsorption

c) $1 \mathrm{~W} \cdot \mathrm{m}^{-1} \cdot \mathrm{K}^{-1}$ thermal conductivity when the sorbent is mixed with up to $20 \mathrm{wt} \%$ expanded natural graphite or other conductivity enhancement material. The target peak excess sorption capacity can be scaled by the factor $\left(1+Y_{E G}\right)$ for the actual weight fraction of ENG required for $1 \mathrm{~W} \cdot \mathrm{m}^{-1} \cdot \mathrm{K}^{-1}$ bed effective thermal conductivity.

d) Above material requirements are to be met when the sorbent-ENG mixture is compacted to $420 \mathrm{~kg} \cdot \mathrm{m}^{-3}$ bulk density.

WTT efficiencies $>55 \%$ with $\operatorname{target} N_{e}^{\max }(77 K)<190 \mathrm{~g}-\mathrm{H}_{2} \cdot \mathrm{kg}^{-1}$ are possible with sorbents that have $E_{l}>5 \mathrm{~kJ} \cdot \mathrm{mol}^{-1}$. Sorbents with $E_{1}>10 \mathrm{~kJ} \cdot \mathrm{mol}^{-1}$ are required for meeting storage systems targets at temperatures approaching $200 \mathrm{~K}$ with WTT efficiencies $>57.5 \%$. The storage pressure can be reduced to 50 bar for sorbents with $E_{1}>6 \mathrm{~kJ} \cdot \mathrm{mol}^{-1}$ and coolant temperature above $135 \mathrm{~K}$. Finally, the sorbents must satisfy additional requirements for cycle life, purity of hydrogen desorbed, toxicity and safety, as specified in storage system targets. The sorbent must also be tolerant to impurities in fuel hydrogen feed, as per related SAE and ISO specifications for fuel cell quality hydrogen.

\section{Acknowledgements}

This work was supported by the Fuel Cell Technologies Office of the U.S. Department of Energy's (DOE) Office of Energy Efficiency and Renewable Energy. Ms. Grace Ordaz was the 
DOE Technology Development Manager for this work. Argonne is a DOE, Office of Science Laboratory operated under Contract No. DE-AC02-06CH11357 by UChicago, Argonne, LLC.

\section{References}

1. Benard $\mathrm{P}$, Chahine R, Determination of the Adsorption Isotherms of Hydrogen on Activated Carbons above the Critical Temperature of the Adsorbate over Wide Temperature and Pressure Ranges, Langmuir 2001; 1950-1955.

2. Stadie NP, Vajo JJ, Cumberland RW, Wilson AA, Ahn CC, Fultz B, Zeolite-Templated Carbon Materials for High-Pressure Hydrogen Storage. Langmuir 2012; 28: 10057-10063.

3. Simpson L, HSCoE Final Report Summary. U.S. Department of Energy Office of Energy Efficiency and Renewable Energy, Fuel Cell Technologies Program, Sept. 30, 2010.

4. Kabbour H, Baumann TF, Satcher JH, Saulnier A, Ahn CC, Towards New Candidates for Hydrogen Storage: High-Surface Area Carbon Aerogels. Chem. Mater. 2006; 18 (26): 60856087.

5. Pfeiffer P, Wexler C, Yu P, Lee M, Robertson D, Firlej L, Kuchta B, Multiply SurfaceFunctionalized Nanoporous Carbon for Vehicular Hydrogen Storage. 2014 DOE Hydrogen and Fuel Cell Technologies Annual Merit Review, Arlington, VA, June 16-120, 2014.

6. Kunowsky M, Marco-Lozar JP, Linares-Solano A, Material Demands for Storage Technologies in a Hydrogen Economy. J. Renewable Energy 2013; Article ID 878329.

7. Snurr R, Hupp J, Kanatzidis M, Nguyen SB, New Carbon-Based Porous Materials with Heats of Adsorption for Hydrogen Storage. FY 2012 Annual Progress Report, DOE Hydrogen and Fuel Cells Program, IV-78 - IV-81, 2012.

8. Langmi HW, Ren J, North B, Mathe M, Bessarabov D, Hydrogen Storage in Metal-Organic Frameworks: A Review. Electrochimica Acta 2014; 128: 368-392. 
9. Rowsell JLC, Yaghi OM, Effects of Functionalization, Catenation, and Variation of the Metal Oxide and Organic Linking Units on the Low-Pressure Hydrogen Adsorption Properties of Metal-Organic Frameworks. J American Chemical Society 2006; 128: 13041315.

10. Han SS, Furukawa H, Yaghi OM, Goddard WA, Covalent Organic Frameworks as Exceptional Hydrogen Storage Materials. J. Am. Chem. Soc. 2008; 138: 11580-11581.

11. Furukawa H, Yaghi OM, Storage of Hydrogen, Methane, and Carbon Dioxide in Highly Porous Covalent Organic Frameworks for Clean Energy Applications. J. Am. Chem. Soc. 2009; 131: 8875-8883.

12. Liu DJ, Yuan S, White D, Mason A, Reprogle B, Hydrogen Storage through Porous Organic Polymers (POPs). FY 2010 Annual Progress Report, DOE Hydrogen and Fuel Cells Program $2011 ; 495-498$.

13. Yuan S, White D, Mason A, Liu DJ, Porous Organic Polymers Containing Carborane for Hydrogen Storage. Int. J. Energy Res. 2013; 37: 732-740.

14. DOE Targets for On-Board Hydrogen Storage Systems for Light-Duty Vehicles, February 2014, published on DOE/FCT website: http://energy.gov/sites/prod/files/2014/03/f12/targets_onboard_hydro_storage.pdf.

15. Ahluwalia RK, Peng, JK, Automotive Hydrogen Storage System using Cryo-Adsorption on Activated Carbon. Int J Hydrogen Energy 2009; 34: 5476-5487.

16. Beckner M, Dailly A, Adsorption Enthalpy Calculations of Hydrogen Adsorption at Ambient Temperature and Pressures Exceeding 300 bar. Am. J. Analytical Chemistry 2013; 4: 8-16.

17. Stadie N, Synthesis and Thermodynamic Studies of Physisorptive Energy Storage Materials. PhD Thesis, California Institute of Technology, 2013. 
18. Zhou W, Wu H, Hartman MR, Yildirim T, Hydrogen and Methane Adsorption in MetalOrganic Frameworks: A High-Pressure Volumetric Study. J. Phys. Chem. C 2007; 111: $16131-16137$.

19. Sudik A, Yang J, Purewal J, Siegel DJ, Leung E, Mueller U, Achieving Optimal Hydrogen Storage In MOF-5, 2010 Annual AIChE Meeting, Salt Lake City, UT, November 2010.

20. Lemmon EW, Huber ML, McLinden MO, NIST Reference Fluid Thermodynamic and Transport Properties Database (REFPROP): Version 8.0, 2007.

21. Bhatia SK, Myers AL, Optimum Conditions for Adsorptive Storage. Langmuir 2006; 22: 1688-1700.

22. Myers AL, Thermodynamics of Adsorption in Porous Materials. AIChE J. 2002; 48(1): 145160.

23. Peng JK, Ahluwalia RK, Enhanced Dormancy due to Para-to-Ortho Hydrogen Conversion in Insulated Cryogenic Pressure Vessels for Automotive Applications. Int J Hydrogen Energy. 2014; 38: 13664-13672.

24. Gear CW, Numerical Initial Value Problems in Ordinary Differential Equations. Englewood Cliffs, NJ: Prentice Hall, 1971.

25. Barron R., Cryogenic Systems. New York, NY: McGraw Hill Book Company, 1996.

26. Ahluwalia RK, Hua TQ, Peng, JK, Fuel Cycle Efficiencies of Different Automotive OnBoard Hydrogen Storage Options. Int J Hydrogen Energy 2007; 32(15): 3592-3602.

27. Ahluwalia R, Hua T, and Peng J, On-board and Off-board Performance of Hydrogen Storage Options for Light-Duty Vehicles, Int. J. Hydrogen Energy 2012; 37: 2891-2910.

28. Essier J, Haberstroh C, Quack H, et al., Integrated Design for Demonstration of Efficient Liquefaction of Hydrogen (IDEALHY). Fuel Cells and Hydrogen Joint Undertaking (FCH JU), Grant Agreement Number 278177, 5 June 2012. 
29. Sterling Power Coolers, Sterling Cryogenics, http://www.stirlingcryogenics.com/products/

30. Knowle, C, Mattick A, Bruckner A, Hertzberg A, High Efficiency Energy Conversion Systems for Liquid Nitrogen Automobiles. SAE Technical Paper 981898, 1998.

31. Advancing Projects and Commercialization of FLNG, Kanfa Aragon Gas Processes, $4^{\text {th }}$ FLNG Asia Pacific Summit, Singapore, June 8-9, 2010.

32. Jakobsen A, Energy Efficiency LNG Technology for Recovery of Flare Gas. Global Forum of Flaring and Venting Reduction and Natural Gas Utilization, Amsterdam, Dec. 3-4, 2008

33. DuPont Suva Technical Information, Using HFC-23 for Very Low temperature (VLT) Refrigeration.

http://www2.dupont.com/Refrigerants/en_US/assets/downloads/h53011_Freon23 for_vlt.pdf

34. DuPont Suva Technical Information, Retrofit Guidelines for Suva 95 (R 508B). http://www2.dupont.com/Refrigerants/en_US/assets/downloads/h65923_Suva95_retrofit_gui de.pdf

35. Ranong C et al., Concept, Design and Manufacture of a Prototype Hydrogen Storage Tank Based on Sodium Alanate. Chem. Eng. Tech. 2009; 32 (8): 1154-1163.

36. Van Hassel B, Mosher D, Pasini J, Gorbounov M, Holowczak J, Tang X, Brown R, Laube B, and Pryor L, Engineering Improvement of $\mathrm{NaAlH}_{4}$ System, Int. J. Hydrogen Energy 2012; 37: 2756-2766.

37. Sanchez A, Klein H, and Groll M, Expanded Graphite as Heat Transfer Matrix in Metal Hydride Beds. Int. J. Hydrogen Energy 2003; 28: 515-517.

38. Liu D, Purewal JJ, Yang J, Sudik A, Maurer S, Mueller U, Ni J, Siegel DJ, MOF-5 Composites Exhibiting Improved Thermal Conductivity. Int. J. Hydrogen Energy 2012; 37: 6109-6117. 
39. Sturabotti E, Low Temperature Liner Materials for Composite Pressure Vessels. Master's Thesis, University of Padova, Italy, 2012.

40. T700S DATA SHEET - Toray Carbon Fibers America. www.toraycfa.com/pdfs/t700sdatasheet.pdf, 2013.

41. Simulia Inc. ABAQUS analysis user's manual; 2011.

42. Roh H, Hua T, and Ahluwalia R, (2013) Optimization of Carbon Fiber Usage in Type 4 Hydrogen Storage Tanks for Fuel Cell Automobiles, Int. J. Hydrogen Energy 2013; 38: 12705-12802.

43. Zickel J, Isotensoid Pressure Vessels, ARS J. 1962; 32: 950-951.

44. Vasiliev V and Morozov E, Mechanics and Analysis of Composite Materials. New York: Elsevier, 2001.

45. Peter S, Humphrey W, and Foral R, Filament Winding: Composite Structure Fabrication. California: SAMPE, 1991.

46. Comond O, Perreux D, Thiebaud F, Weber M, Methodology to Improve the Lifetime of Type III HP Tank with a Steel Liner. Int. J. Hydrogen Energy 2009; 34:3077-309.

47. UN GTR, Proposal for a Global Technical Regulation on Hydrogen and Fuel Cell Vehicles. ECE/TRANS/WP.29/2013/41.

48. Hua T, Ahluwalia R, Peng J, Kromer M, Lasher S, McKenney K, Law K, and Sinha J, Technical Assessment of Compressed Hydrogen Storage Tank Systems for Automotive Applications. Int. J. Hydrogen Energy 2011; 36: 3037-3049.

49. Veenstra M, Yang J, Xu C, Ford/BASF-SE/UM Activities in Support of the Hydrogen Storage Engineering Center of Excellence. 2014 DOE Annual Merit Review Meeting, Arlington, VA, June 18, 2014 
Table 1: Abbreviated List of Technical Targets for On-board Hydrogen Storage Systems for Light-Duty Fuel Cell Vehicles

Storage Parameter

\section{System Gravimetric Capacity}

Usable, specific-energy from $\mathrm{H}_{2}$

(net useful energy/max system mass)

\section{System Volumetric Capacity}

Usable energy density from $\mathrm{H}_{2}$

(net useful energy/max system volume)

\section{Durability/Operability}

Operating ambient temperature

Min/max delivery temperature

Operational cycle life (1/4 tank to full)

Min delivery pressure from storage system

Max delivery pressure from storage system

Charging/Discharging Rates

System refueling rate

Minimum full flow rate
Units $2017 \quad$ Ultimate

$\begin{array}{ccc}\mathrm{kWh} / \mathrm{kg} & 1.8 & 2.5 \\ \left(\mathrm{~kg} \mathrm{H}_{2} / \mathrm{kg} \mathrm{system}\right) & (0.055) & (0.075)\end{array}$

$\mathrm{kWh} / \mathrm{L}$

1.3

2.3

( $\mathrm{kg} \mathrm{H}_{2} /$ L system) (0.040)

${ }^{\circ} \mathrm{C}$

$-40 / 60 \quad-40 / 60$

${ }^{\circ} \mathrm{C}$

$-40 / 85$

$-40 / 85$

Cycles

1500

1500

atm (abs)

5

3

atm (abs)

12

12

$\mathrm{kg} \mathrm{H}_{2} / \mathrm{min}$

1.5

2

(g/s)/kW

0.02

0.02 
Table 2: Langmuir Constants for $\mathrm{H}_{2}$ Adorption on MOF-5

$\begin{array}{cccccccc} & N_{\max } & \alpha & v_{a} & C_{1} & E_{1} & C_{2} & E_{2} \\ & \mathrm{~g}-\mathrm{H}_{2} \cdot \mathrm{kg}^{-1} & & \mathrm{~m}^{3} \cdot \mathrm{kg}^{-1} & \text { atm. } \mathrm{K}^{0.5} & \mathrm{~kJ} \cdot \mathrm{mol}^{-1} & \text { atm. } \mathrm{K}^{0.5} & \mathrm{~kJ} \cdot \mathrm{mol}^{-1} \\ \text { Double Langmuir Equation } & 118.8 & 0.51 & 0.0132 & 0.0021 & 2.76 & 0.0038 & 3.9 \\ \text { Single Langmuir Equation } & 106.0 & 1.0 & 0.0125 & 0.0053 & 3.13 & - & -\end{array}$


Table 3: Hydrogen Production and Delivery Pathway

\begin{tabular}{|c|c|c|}
\hline Process & Assumptions & Source \\
\hline $\mathrm{H}_{2}$ Production at $20 \mathrm{bar}$ & SMR at central plant, $73 \%$ efficiency & $\mathrm{H} 2 \mathrm{~A}^{1}$ \\
\hline $\mathrm{H}_{2}$ compression at central plant & Compressor efficiency $88 \%$ & FCHtool [26] \\
\hline $\mathrm{H}_{2}$ delivery to forecourt & Pipeline, 50 bar pressure drop & HDSAM $^{1}$ \\
\hline $\mathrm{H}_{2}$ compression at forecourt & Compressor efficiency $65 \%$ & FCHtool \\
\hline Cooling at forecourt & COP a function of temperature & Various [28 - 34] \\
\hline \multirow[t]{2}{*}{ Electricity generation } & $35 \%$ efficiency & U.S. grid 2015 \\
\hline & $8 \%$ transmission loss & GREET $^{1}$ \\
\hline $\begin{array}{l}{ }^{1} \text { Paster MD, Ahluwalia RK, Berr } \\
\text { Hydrogen Storage Technology C } \\
\text { Efficiencies, and Greenhouse Ga } \\
\text { 14534-14551. }\end{array}$ & $\begin{array}{l}\text { A, Elgowainy A, Lasher S, McKenne } \\
\text { tions for Fuel Cell Vehicles: Well-to- } \\
\text { Emissions. Int J Hydrogen Energy } 2\end{array}$ & $\begin{array}{l}\text { Gardiner M, } \\
\text { el Costs, Energy } \\
\text {; } 36 \text { (22): }\end{array}$ \\
\hline
\end{tabular}




\section{Table 4. COP Data for Industrial and Commercial COP Refrigeration Systems}

\begin{tabular}{|c|c|c|c|c|}
\hline $\begin{array}{l}\text { Refrigeration } \\
\text { System }\end{array}$ & $\mathrm{T}, \mathrm{K}$ & Capacity, $\mathrm{kW}_{\mathrm{t}}$ & $\mathrm{COP}$ & Comments \\
\hline \multirow[t]{2}{*}{$\mathrm{LH}_{2}$} & 20 & 200 & 0.081 & Linde Ingolstadt (1992), $13.6 \mathrm{kWh} / \mathrm{kg}, 4.4 \mathrm{t} / \mathrm{d}$ \\
\hline & 20 & 225 & 0.092 & Linde Leuna (2007), $11.9 \mathrm{kWh} / \mathrm{kg}, 4.9 \mathrm{t} / \mathrm{d}$ \\
\hline \multirow[t]{3}{*}{$\mathrm{LN}_{2}$} & 65 & $0.5-2.5$ & $0.037-0.046$ & Stirling Power Cooler, Stirling Cryogenics \\
\hline & 77 & $0.8-7.3$ & $0.070-0.077$ & Stirling Power Cooler, Stirling Cryogenics \\
\hline & 77 & 24,000 & 0.234 & Large air separation plant, $0.5 \mathrm{kWh} / \mathrm{kg}, 4860 \mathrm{t} / \mathrm{d}$ \\
\hline \multirow[t]{3}{*}{ LNG } & 110 & $34-85$ & 0.42 & Hamworthy Mini LNG, 6-15 t/d, 0.6 kWh/kg, SINTEF \\
\hline & 110 & 17,000 & $0.46-0.632$ & Kanfa Aragon N2 expander cycle, $0.4-0.55 \mathrm{kWh} / \mathrm{kg}, 3000 \mathrm{t} / \mathrm{d}$ \\
\hline & 110 & 17,000 & 0.843 & Aragon Dual Cascade mixed refrigerant, $0.3 \mathrm{kWh} / \mathrm{kg}, 3000 \mathrm{t} / \mathrm{d}$ \\
\hline VLT: R-503 & $178-197$ & $0.2-1.9$ & $0.2-0.94$ & VLT refrigeration, DuPont, ozone depleter, higher capacity than R-13 \\
\hline VLT: R-13 & $178-197$ & $0.1-1.2$ & $0.25-0.78$ & DuPont, ozone depleter, to be phased out \\
\hline VLT: HFC-23 & $189-197$ & $0.1-1.6$ & 0.86 & Freon $23, \mathrm{CFC}$ free, $10 \%$ higher energy consumption than R-503 \\
\hline \multirow{3}{*}{$\begin{array}{l}\text { Commercial } \\
\text { Refrigerated } \\
\text { Storage }\end{array}$} & $230-245$ & 5 & $1.59-2.06$ & ANSI / AHRI standard refrigerated storage contaniners, cabinets \\
\hline & $250-260$ & 5 & $2.34-3.06$ & ANSI/AHRI Standard 1210 \\
\hline & $265-275$ & 5 & $3.55-4.86$ & Ratings approved by ANSI in Jan 2011 \\
\hline
\end{tabular}


Table 5: Properties of T700S Carbon Fiber and Composite (60\% Fiber Volume)

$\begin{array}{lccc}\text { Property } & \text { Unit } & \text { Fiber } & \text { Composite } \\ \text { Tensile Strength } & \mathrm{MPa} & 4900 & 2550 \\ \text { Tensile Modulus } & \mathrm{GPa} & 230 & 135 \\ \text { Tensile Strain } & \% & 2.1 & 1.7 \\ \text { Density } & \mathrm{kg} / \mathrm{m}^{3} & 1800 & 1580 \\ \text { Compressive Strength } & \mathrm{MPa} & & 1470 \\ \text { Flexural Strength } & \mathrm{MPa} & & 1670 \\ \text { Flexural Modulus } & \mathrm{GPa} & & 120\end{array}$




\section{Table 6: Study Parameters}

\begin{tabular}{|c|c|c|c|c|c|}
\hline & & Units & $\begin{array}{c}\text { Reference } \\
\text { Values }\end{array}$ & $\begin{array}{c}\text { Range of } \\
\text { Values }\end{array}$ & Comments \\
\hline \multirow[t]{6}{*}{ Sorbent } & Excess Uptake at $77 \mathrm{~K}$ & $\mathrm{~g}-\mathrm{H}_{2} \cdot \mathrm{kg}^{-1}$ & 100 & $100-250$ & NU-100 [7] \\
\hline & Differential Enthalpy Parameter $\left(E_{1}\right)$ & $\mathrm{kJ} / \mathrm{mol}$ & 5.0 & $2.5-10$ & MOF-5: $3.1 \mathrm{~kJ} / \mathrm{mol}$ \\
\hline & Adsorption Volume & $\mathrm{m}^{3} \cdot \mathrm{kg}^{-1}$ & 0.012 & TBD & MOF-5 \\
\hline & Molar Entropy Parameter $\left(\mathrm{C}_{1}\right)$ & $\operatorname{atm} \cdot \mathrm{K}^{1 / 2}$ & 0.0053 & 0.0053 & MOF-5, $\Delta s_{a} / R \sim 8$ \\
\hline & Bulk Density of Compact & $\mathrm{kg} \cdot \mathrm{m}^{-3}$ & TBD & $310-610$ & IJHE 37 (2012) 2723-2727 \\
\hline & Permeability & $\mathrm{m}^{2}$ & TBD & TBD & IJHE 38 (2013) 3268-3274 \\
\hline Operating & Off-board Coolant Temperature & $\mathrm{K}$ & 77 & $77-200$ & LN2 - ANSI/ASHRI \\
\hline \multirow[t]{2}{*}{ Temperatures } & Storage Temperature & $\mathrm{K}$ & TBD & TBD & \\
\hline & Temperature Swing & $\mathrm{K}$ & TBD & TBD & \\
\hline Operating & Storage Pressure & bar & 100 & $50-200$ & \\
\hline Pressures & Minimum Delivery Pressure & bar & 5 & & DOE target \\
\hline \multirow[t]{2}{*}{$\mathrm{H}_{2}$ Flow Rates } & Refueling Rate & $\mathrm{kg} \cdot \min ^{-1}$ & 1.5 & & DOE target \\
\hline & Minimum Full Flow Rate & $g / s$ & 1.6 & & DOE target \\
\hline \multirow[t]{2}{*}{ Heat Transfer } & ENG/Sorbent Mass Ratio & & 0.2 & $0.1-0.3$ & \\
\hline & Number of $\mathrm{HX}$ Tubes & & TBD & TBD & \\
\hline
\end{tabular}


Table 7: Reference Material Targets

\begin{tabular}{|c|c|c|c|}
\hline Independent Variables & Related Variables & Reference Values & System Constraints \\
\hline \multicolumn{4}{|l|}{ Material Properties } \\
\hline Excess Uptake at $77 \mathrm{~K}$ & $\mathrm{E}_{1}=5 \mathrm{~kJ} \cdot \mathrm{mol}^{-1}$ & $190 \mathrm{~g}-\mathrm{H}_{2} \cdot \mathrm{kg}^{-1}$ & 5.5 wt\% gravimetric capacity \\
\hline \multirow[t]{3}{*}{ Fill Ratio } & Bed Porosity & $67 \%$ & $40 \mathrm{~g} / \mathrm{L}$ volumetric capacity \\
\hline & Bulk Density & $420 \mathrm{~kg} \cdot \mathrm{m}^{-3}$ & \\
\hline & Thermal Conductivity & $1 \mathrm{~W} / \mathrm{m} . \mathrm{K}$ & \\
\hline \multicolumn{4}{|c|}{ Operating Temperatures } \\
\hline Off-board Coolant & WTT Efficiency & $135 \mathrm{~K}$ & >55\% WTT efficiency \\
\hline Storage Temperature & & $155 \mathrm{~K}$ & \\
\hline Temperature Swing & Usable $\mathrm{H}_{2}$ & $60 \mathrm{~K}$ & $95 \%$ usable $\mathrm{H}_{2}$ \\
\hline \multicolumn{4}{|l|}{ System Variables } \\
\hline \multirow[t]{2}{*}{ Mass of Sorbent } & Sorbent & $42 \mathrm{~kg}$ & $5.6 \mathrm{~kg}$ usable $\mathrm{H}_{2}$ \\
\hline & ENG & $8.4 \mathrm{~kg}$ & \\
\hline \multirow[t]{2}{*}{ HX Tube Spacing } & Number of $\mathrm{HX}$ Tubes & $d_{m} / d_{f}=3.4$ & $1.5 \mathrm{~kg} \cdot \mathrm{min}^{-1}$ refueling rate \\
\hline & & $112 U$ tubes & \\
\hline
\end{tabular}


Table 8: Refueling Conditions

$\begin{array}{lccccc} & P & T & N_{e} & \rho_{g} & \rho_{H_{2}}=\varepsilon_{v} \rho_{g}+\rho_{s} N_{e} \\ & \text { bar } & \mathrm{K} & \mathrm{g}-\mathrm{H}_{2} \cdot \mathrm{kg}^{-1} & \mathrm{~kg} \cdot \mathrm{m}^{-3} & \mathrm{~kg} \cdot \mathrm{m}^{-3} \\ \text { Fully Discharged } & 5 & 215 & 6.1 & 0.6 & 2.9 \\ \text { Charged: Phase 1 } & 100 & 214 & 69 & 10.7 & 36.1 \\ \text { Fully Charged } & 100 & 155 & 116.6 & 14.7 & 58.8\end{array}$




\section{Table 9: Summary of Material Requirements and Operating Conditions}

\section{Symbols Levels ${ }^{4}$ Material Targets Related System Targets Comments}

\section{Operating Pressures and Temperatures}

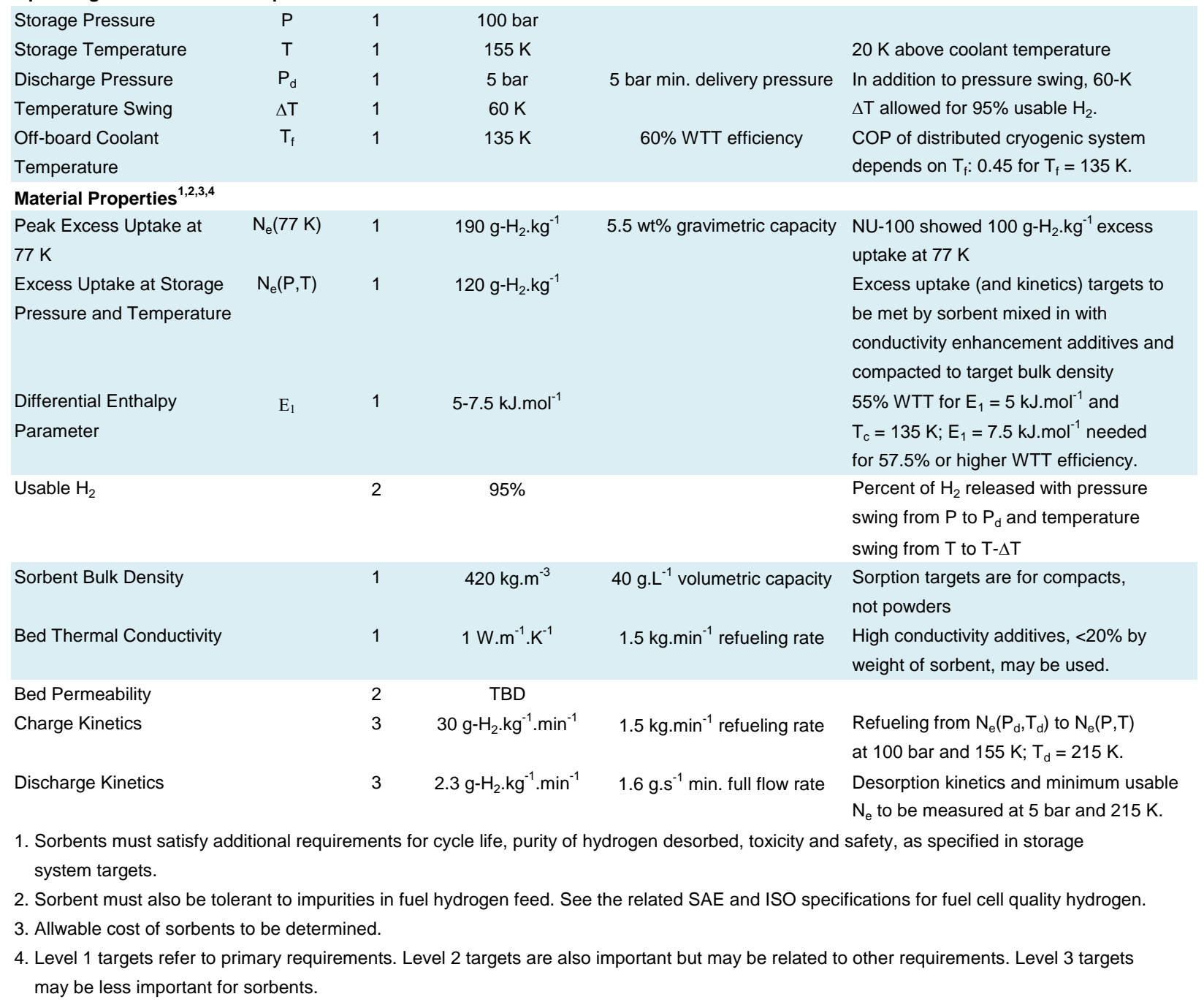




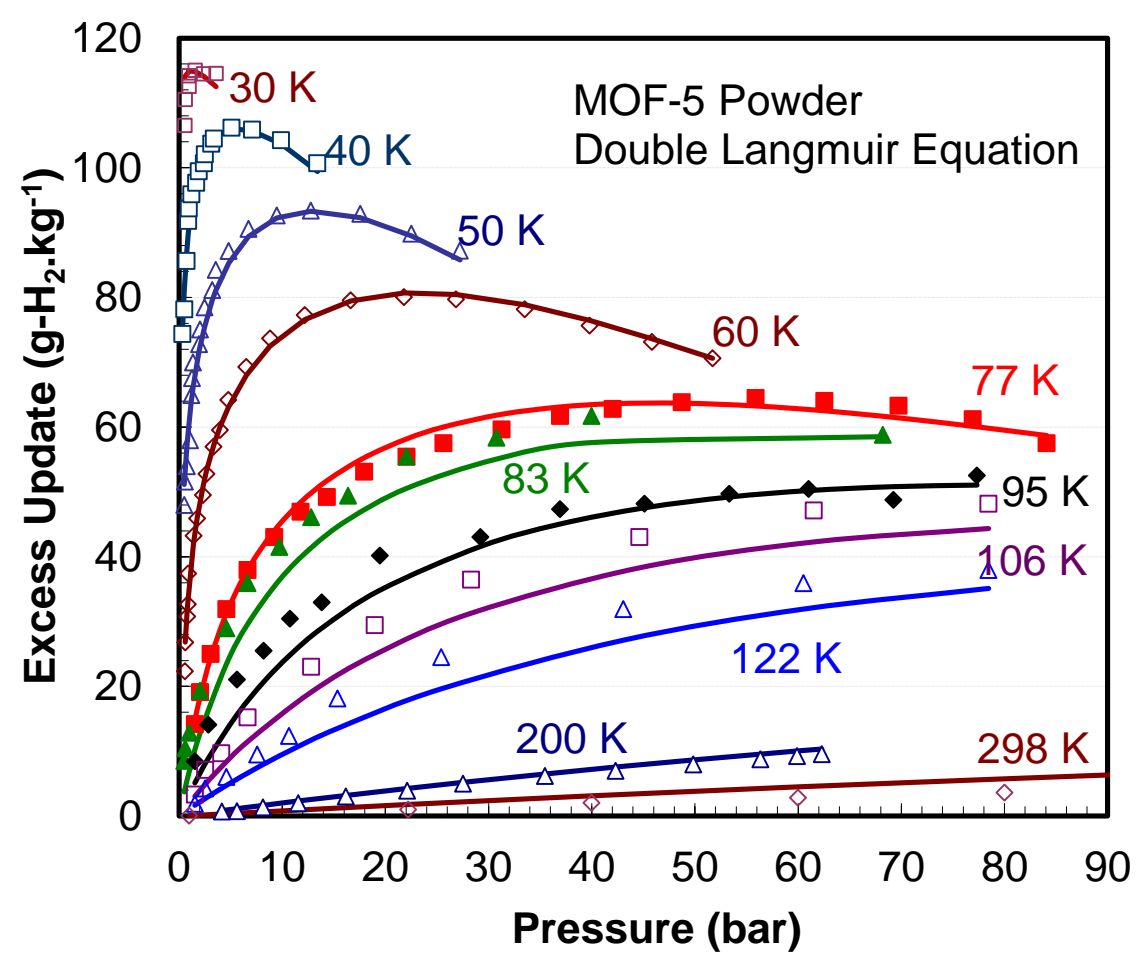

(1a) Double Langmuir isotherm

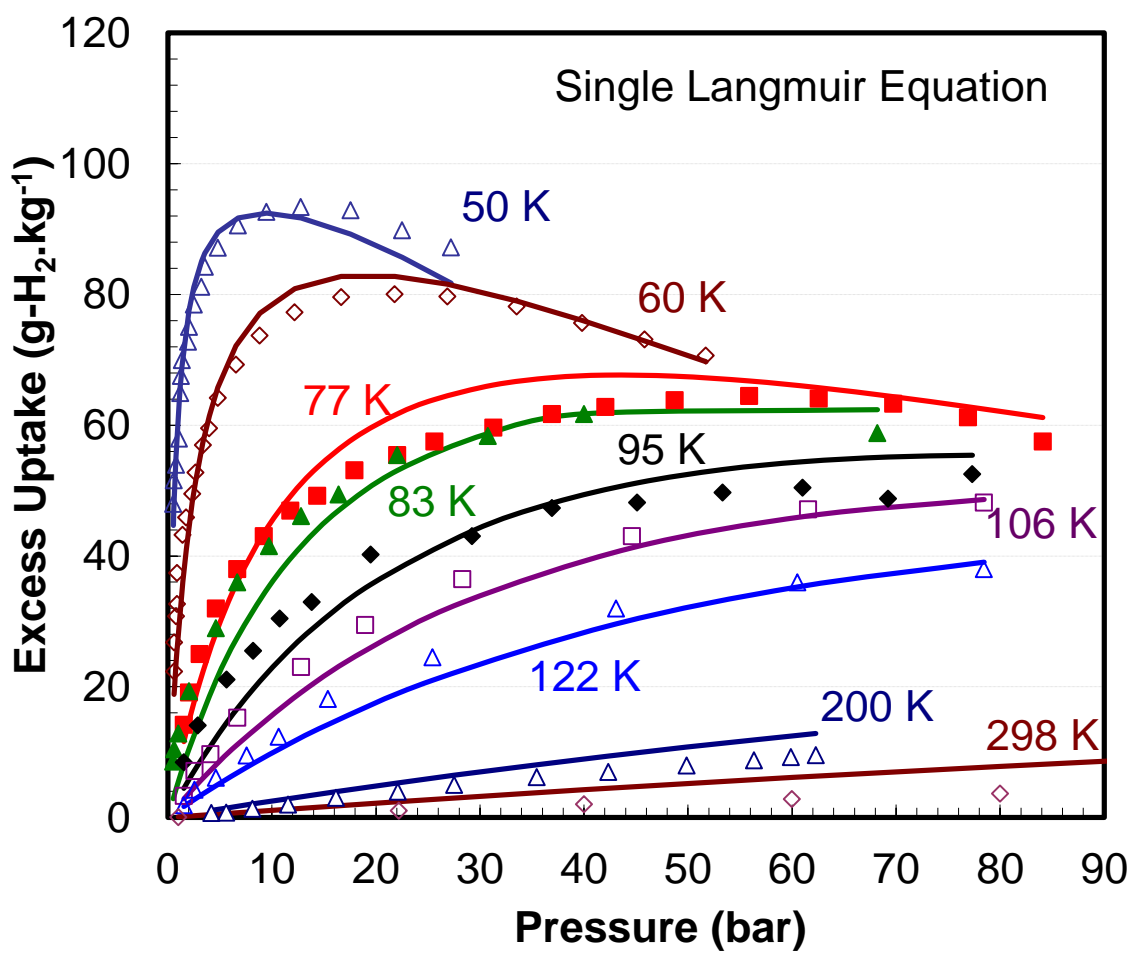

(1b) Single Langmuir isotherm

Figure 1 Langmuir adsorption isotherms for $\mathrm{H}_{2}$ uptake on MOF-5. Data from Zhou et al [18] and Sudik et al [19]. 


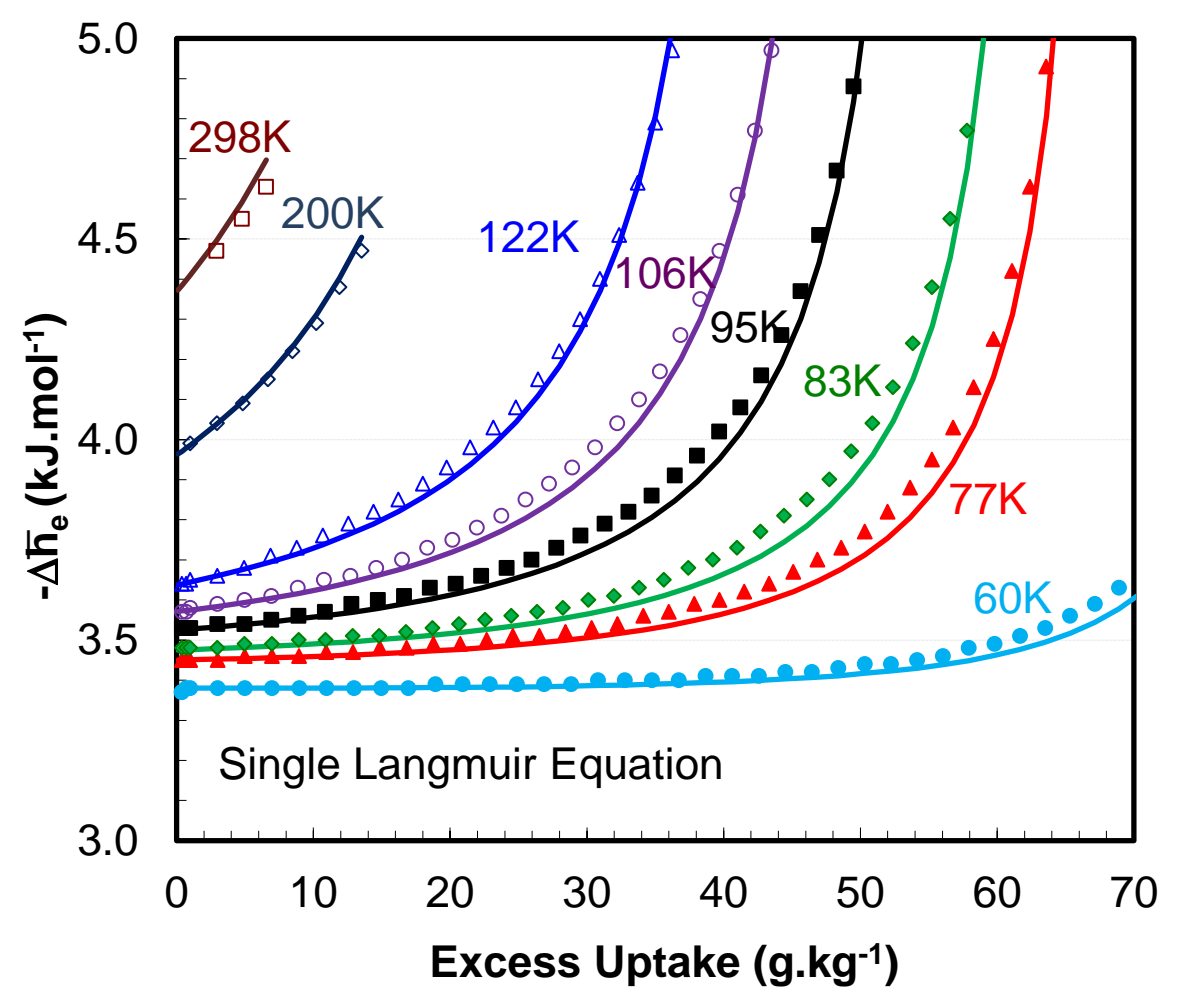

(2a) Differential enthalpy of adsorption

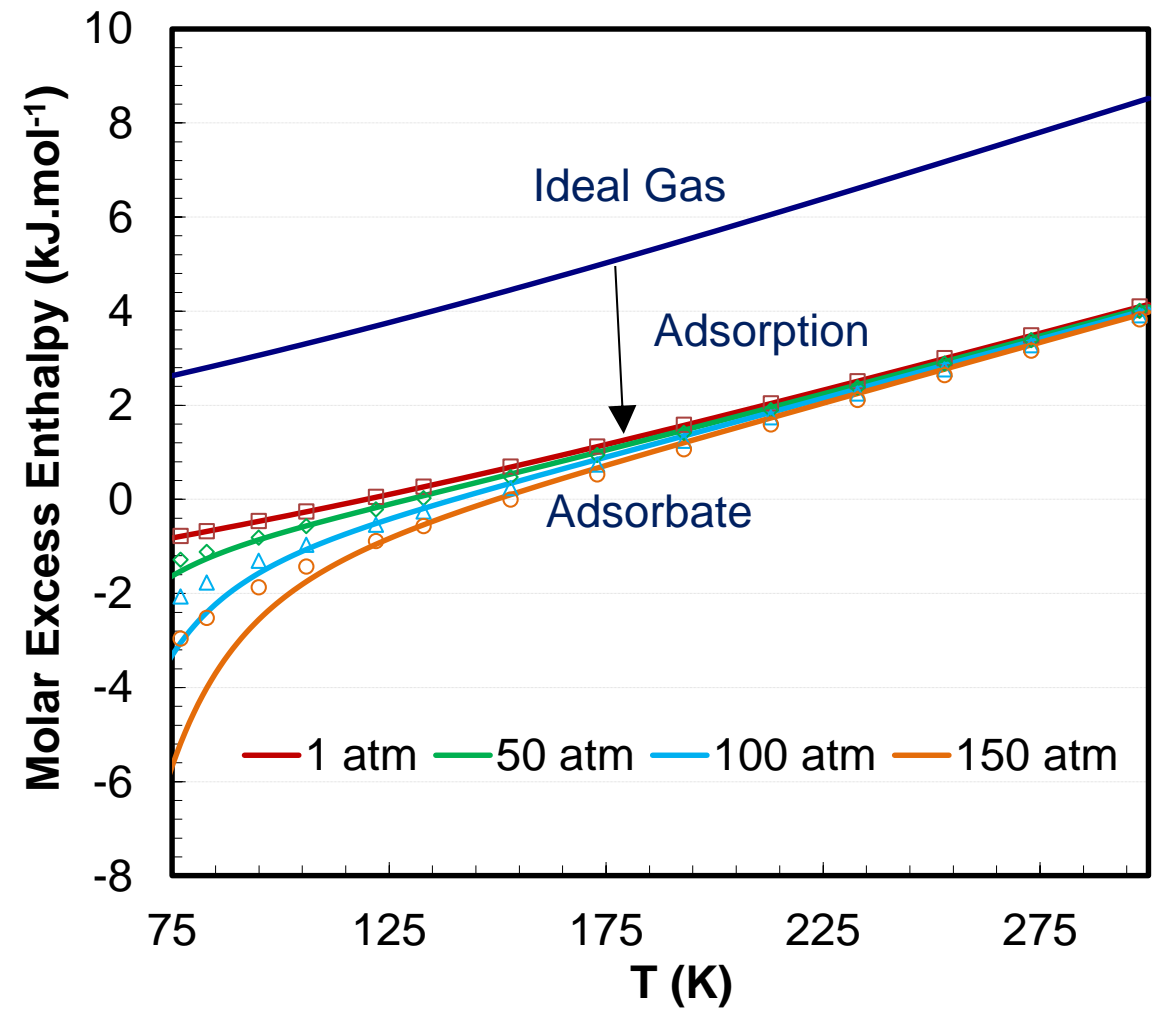

(2b) Molar excess enthalpy

Figure 2 Thermodynamics of $\mathrm{H}_{2}$ uptake on MOF-5 using single Langmuir equation. Symbols denote results from Eqs. (10) and (11). 


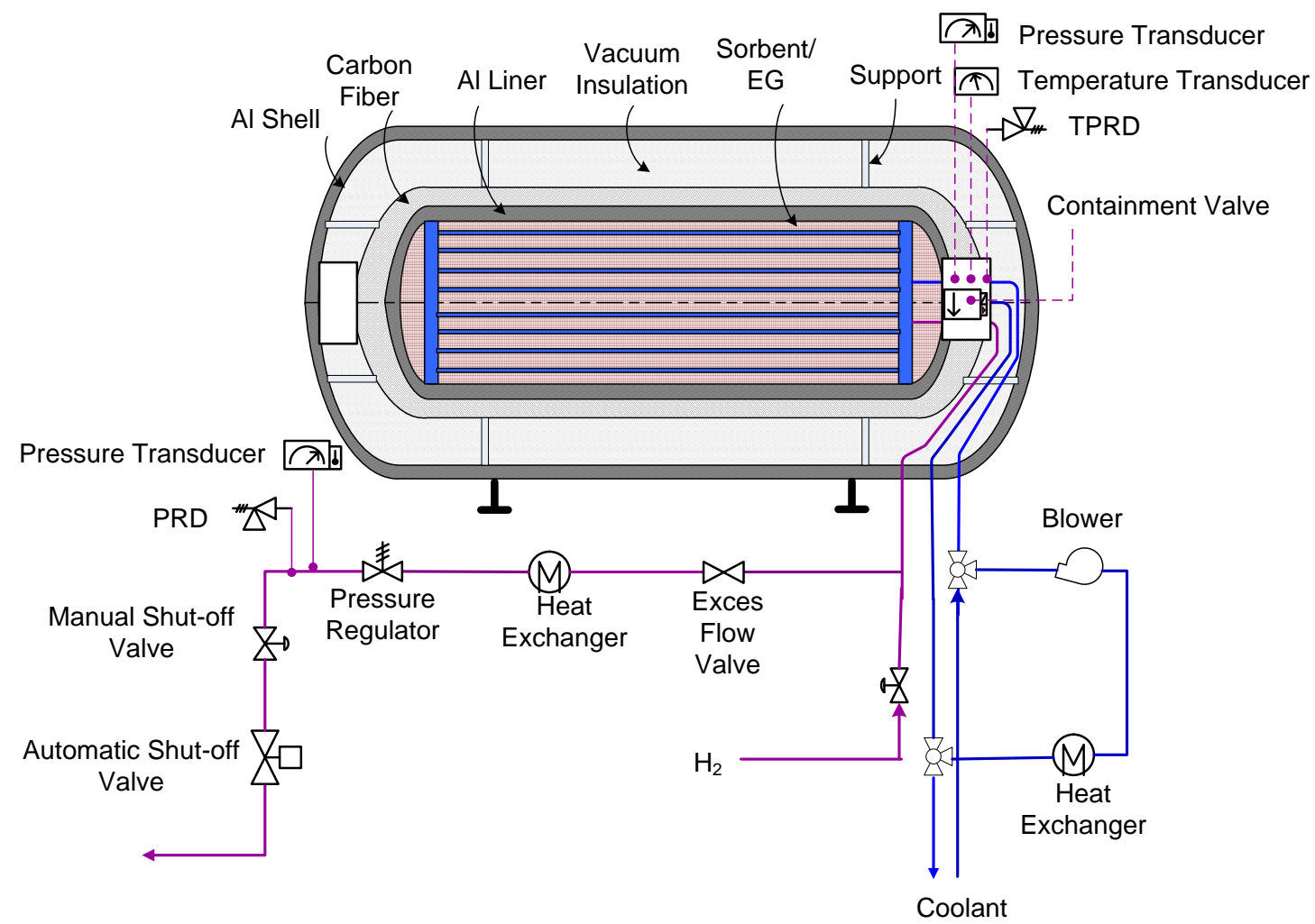

Figure 3 On-board storage system 


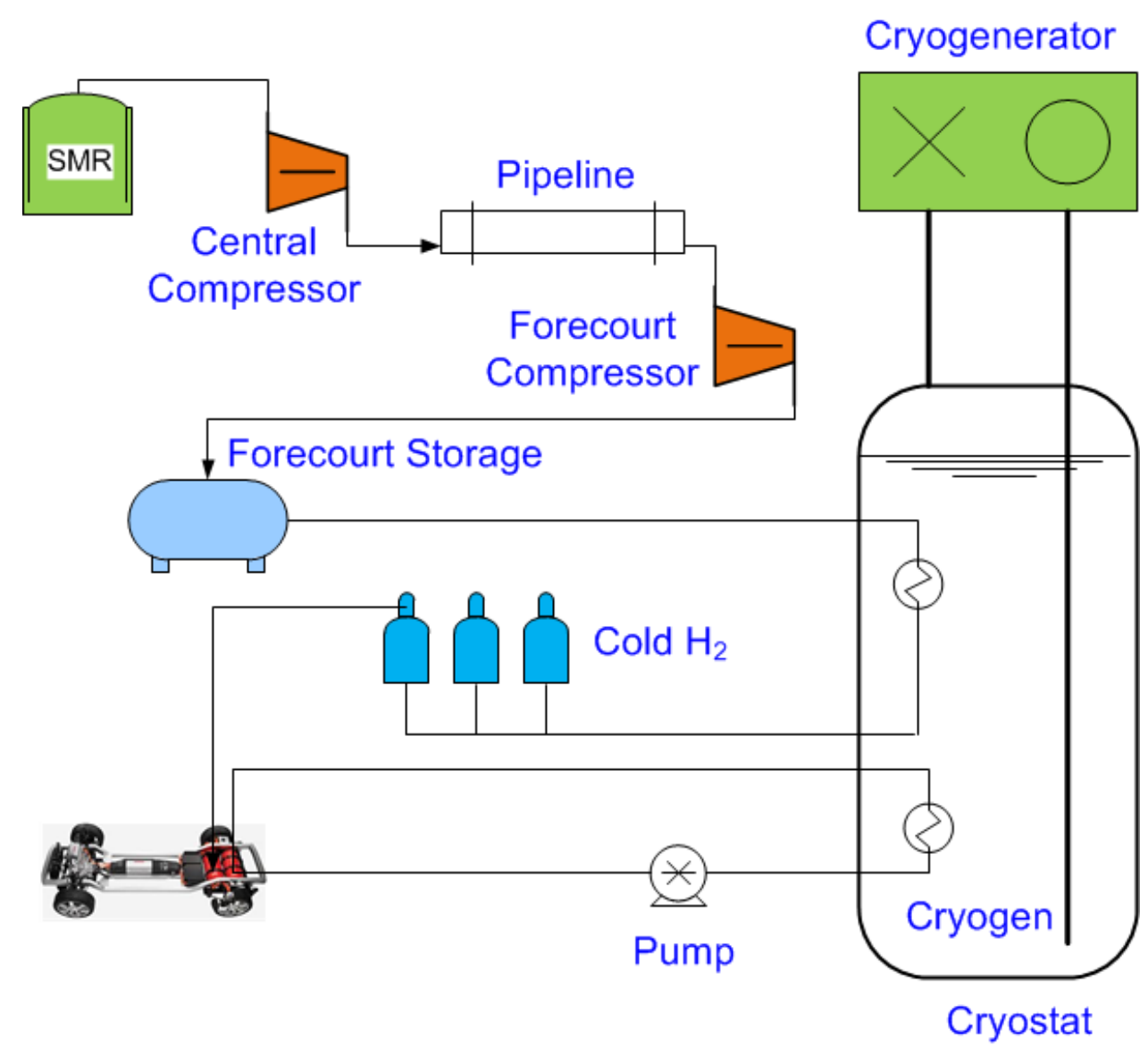

Figure 4 Refueling interface 


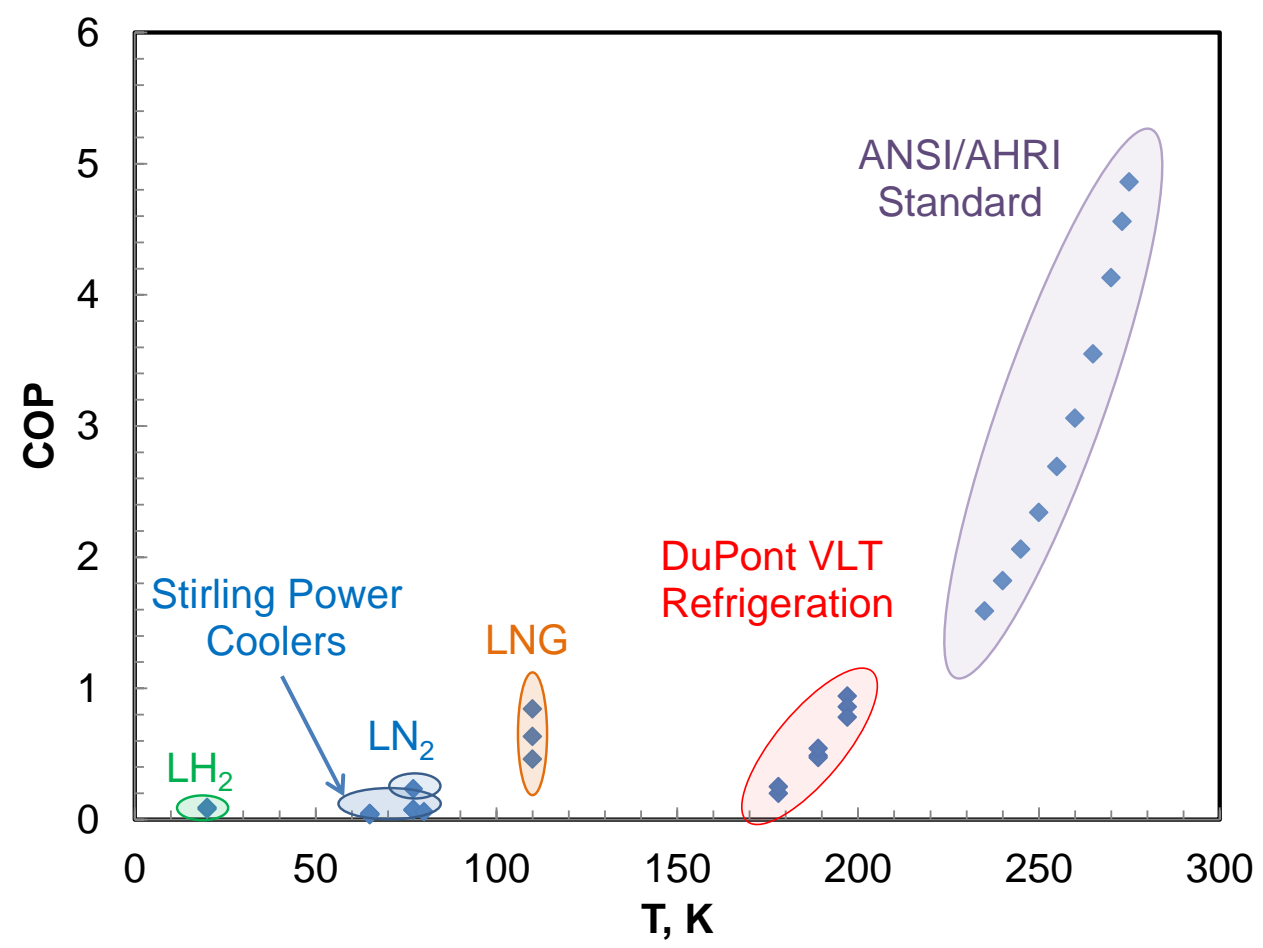

(5a) COP vs. refrigeration temperature

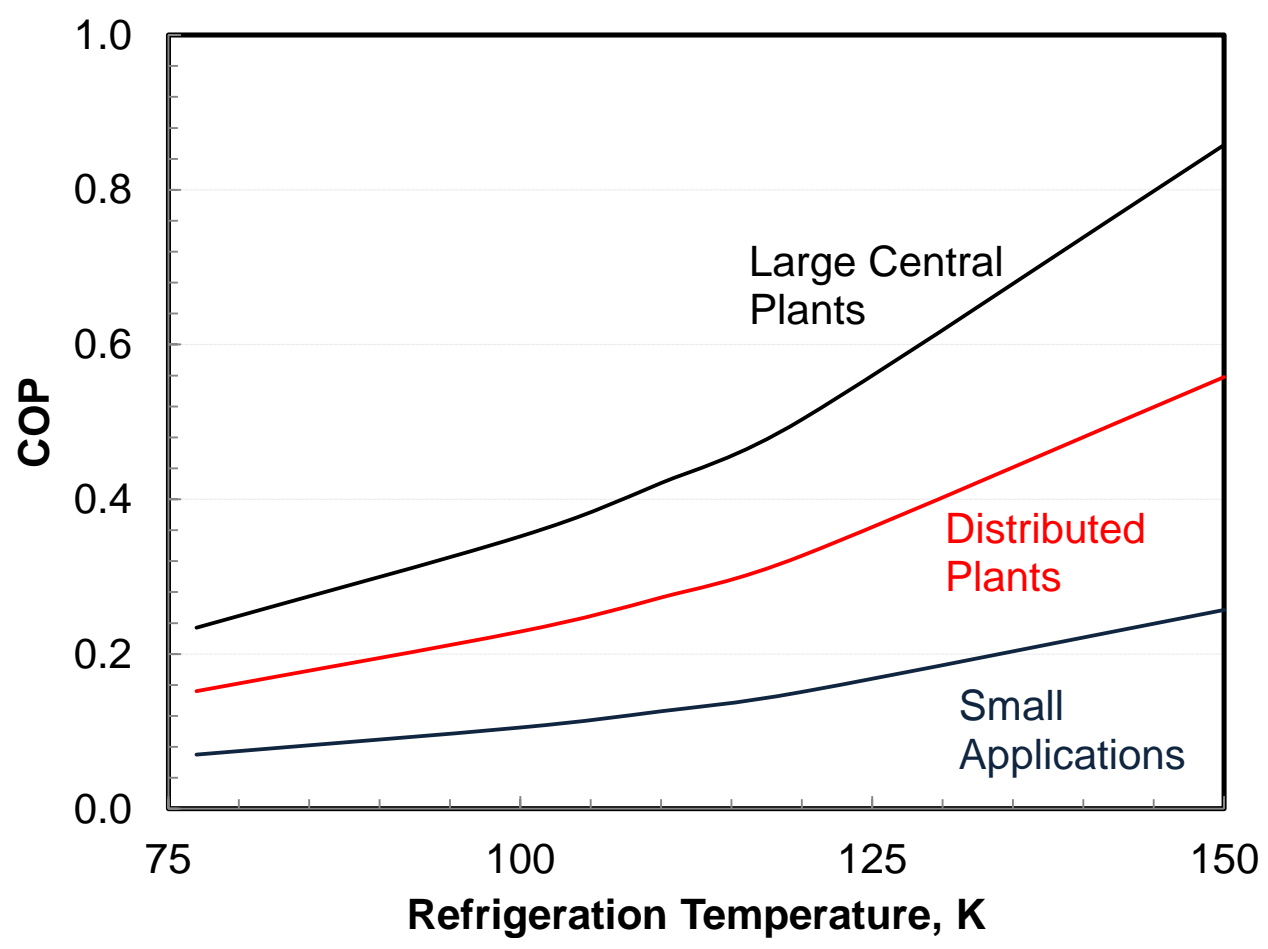

(5b) COP correlation

Figure 5 Correlation of COP with size and temperature using literature data for small and large industrial and commercial refrigeration systems 


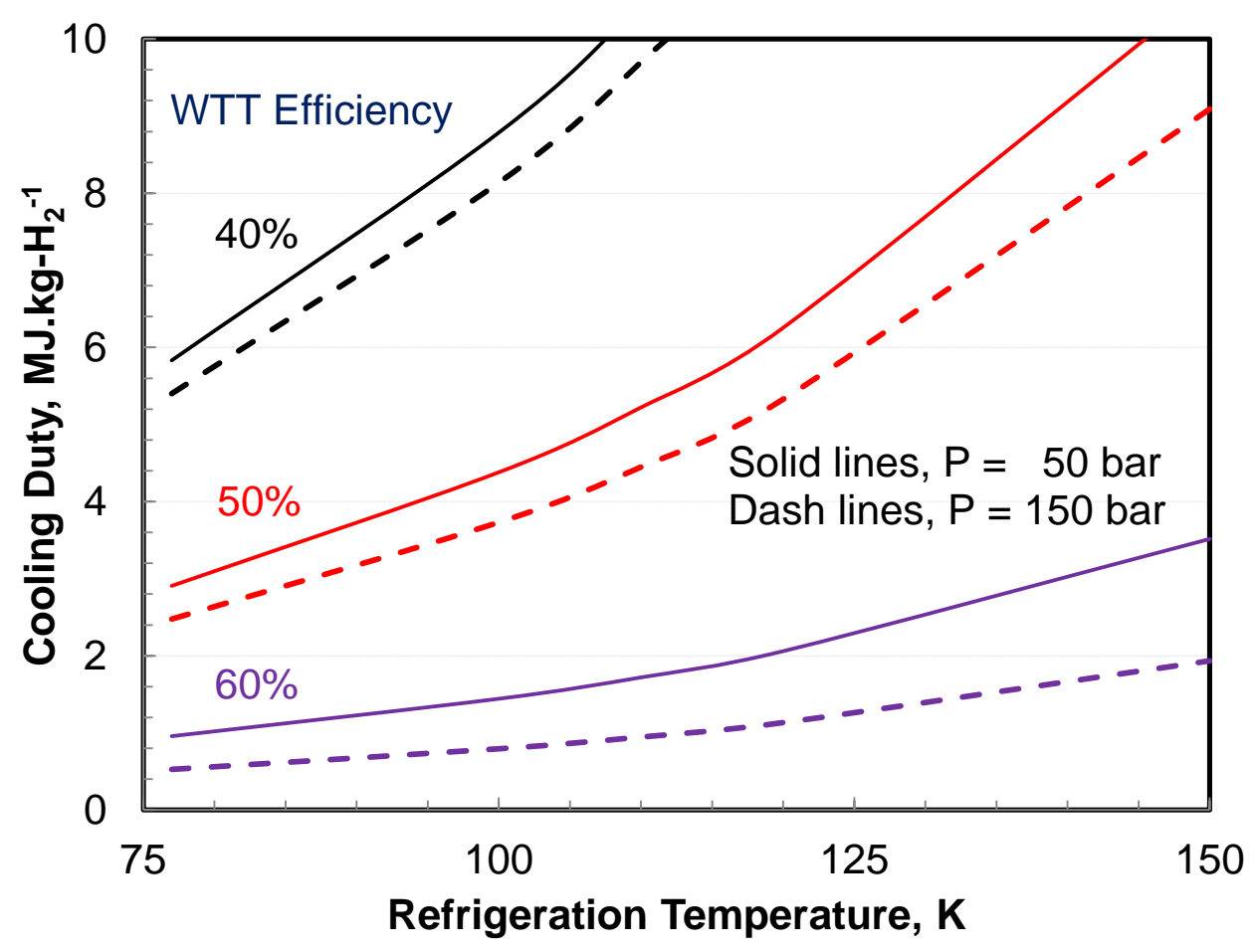

Figure 6 Allowable cooling duty correlated with WTT efficiency and refrigeration temperature 


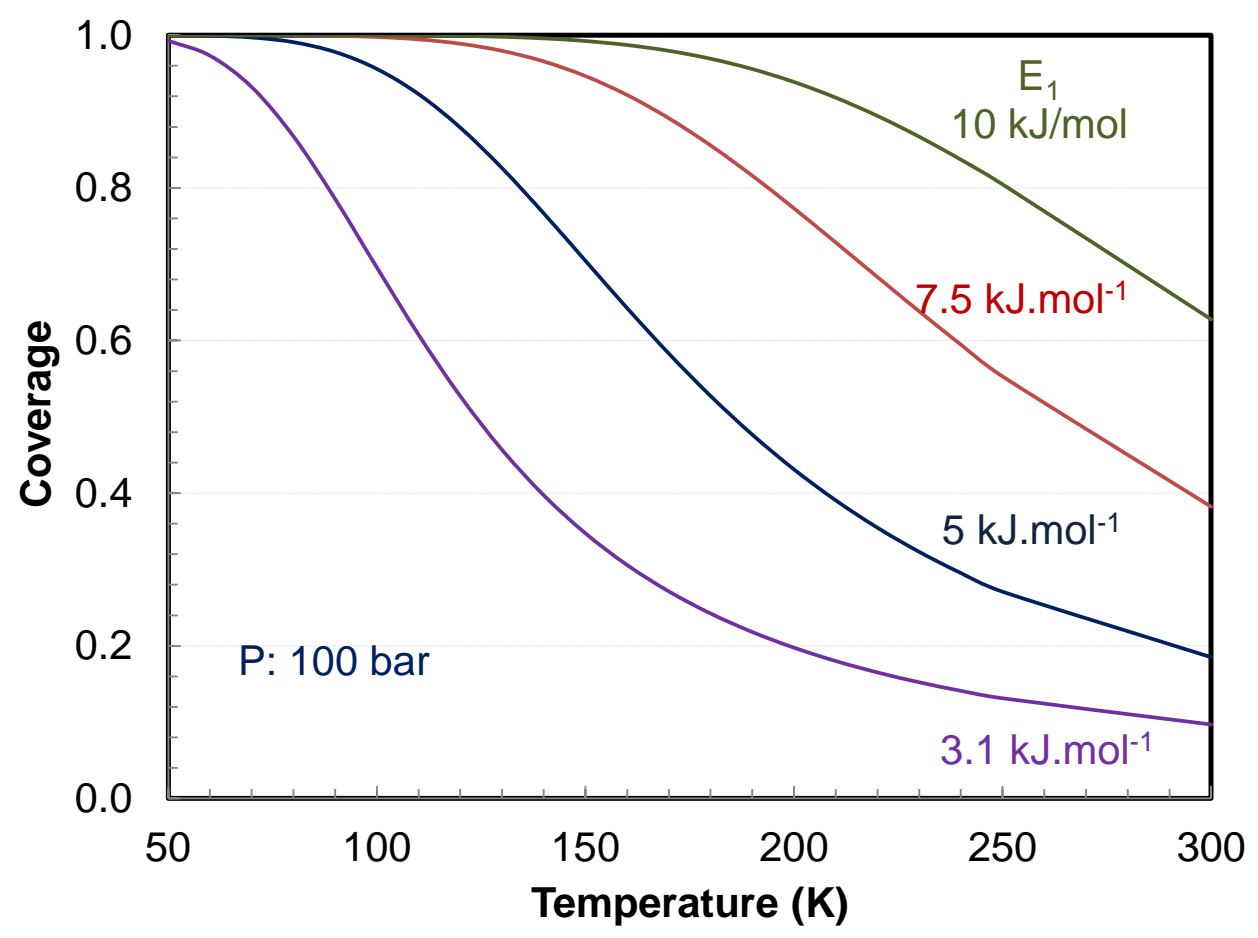

(7a) Coverage at 100 bar

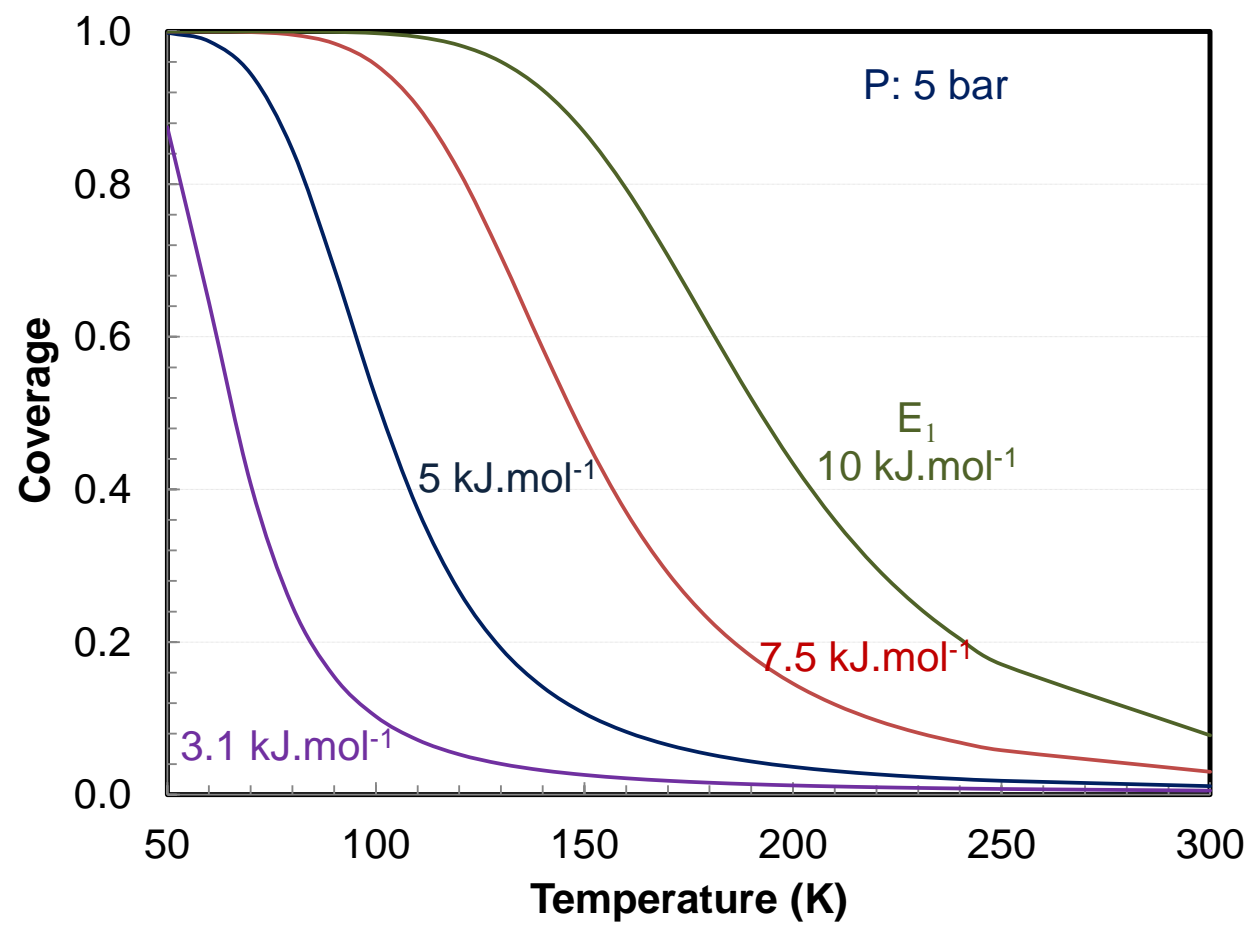

(7b) Coverage at 5 bar

Figure 7 Variation of coverage with operating pressures and temperatures 


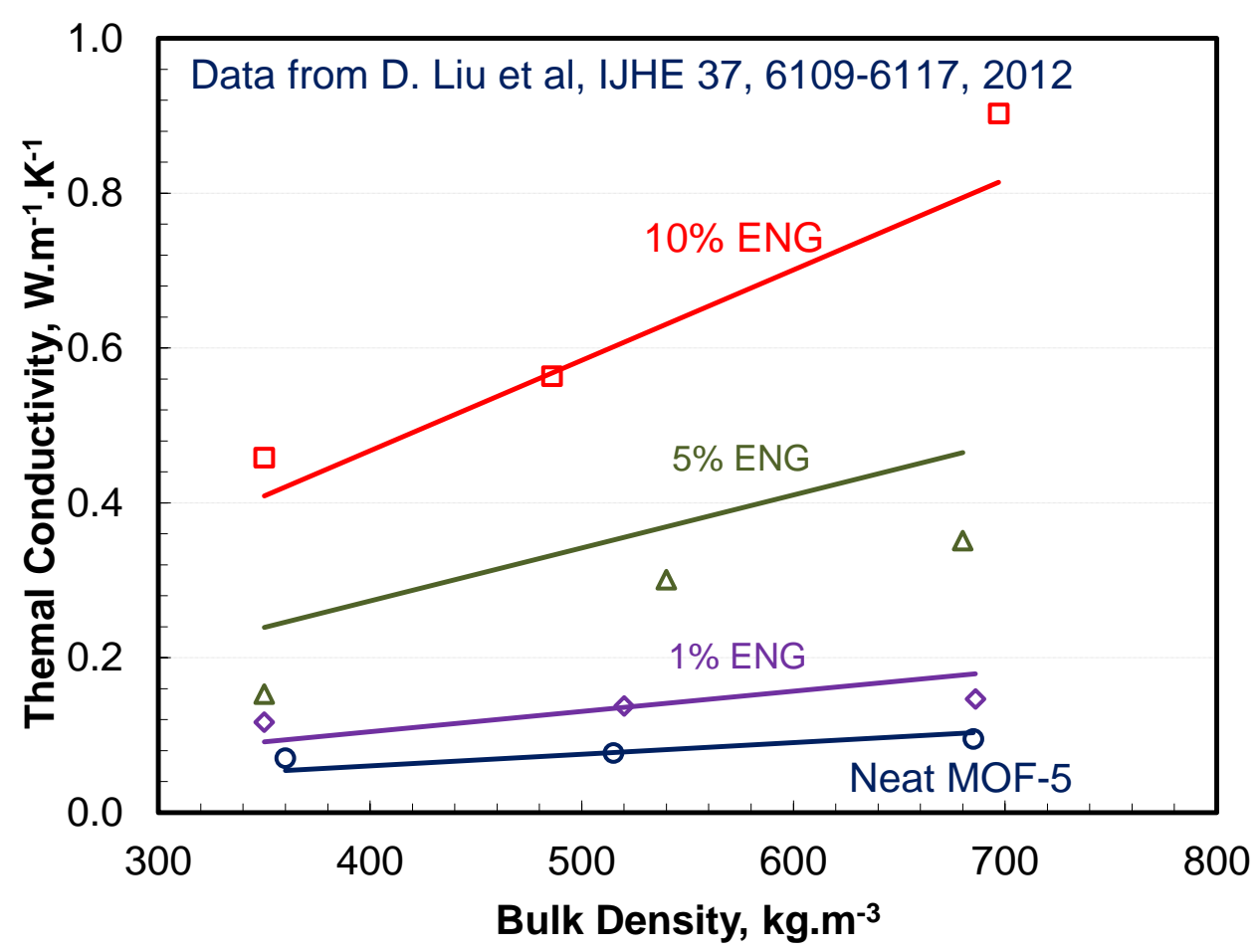

Figure 8 Thermal conductivity of sorbent consolidated with expanded natural graphite 


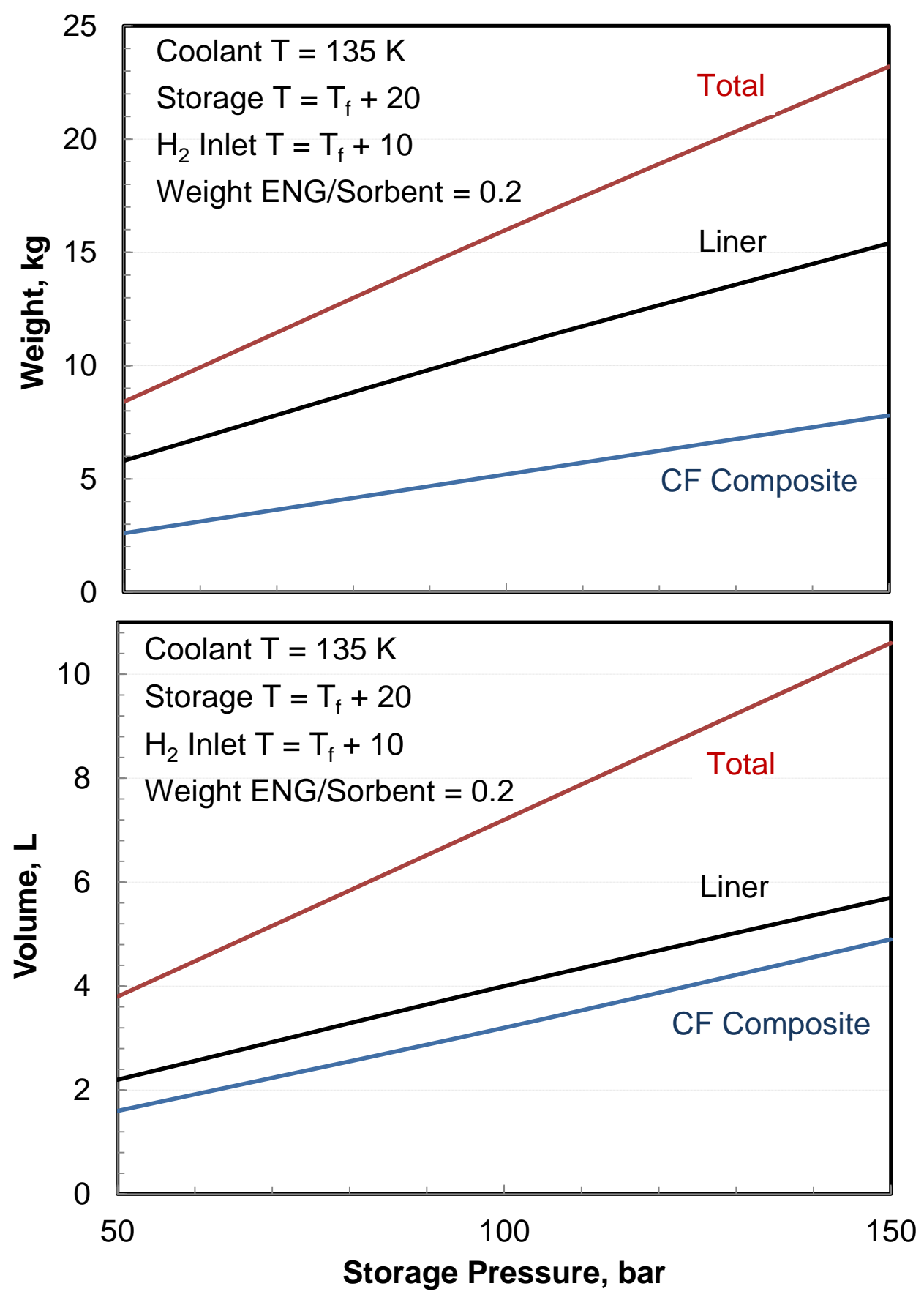

Figure 9 Weight and volume of Type-3 containment tank 


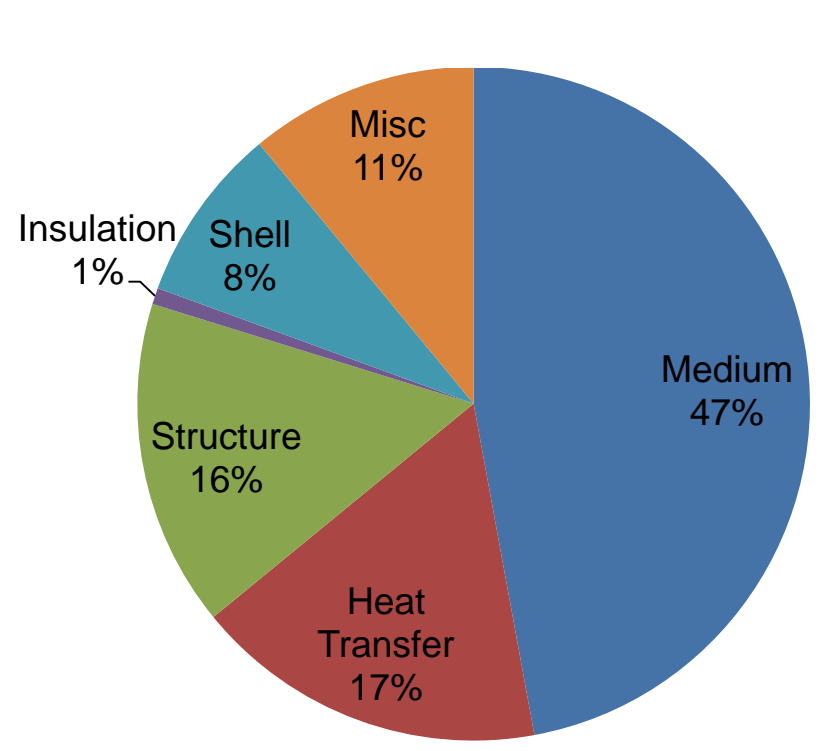

Component weights

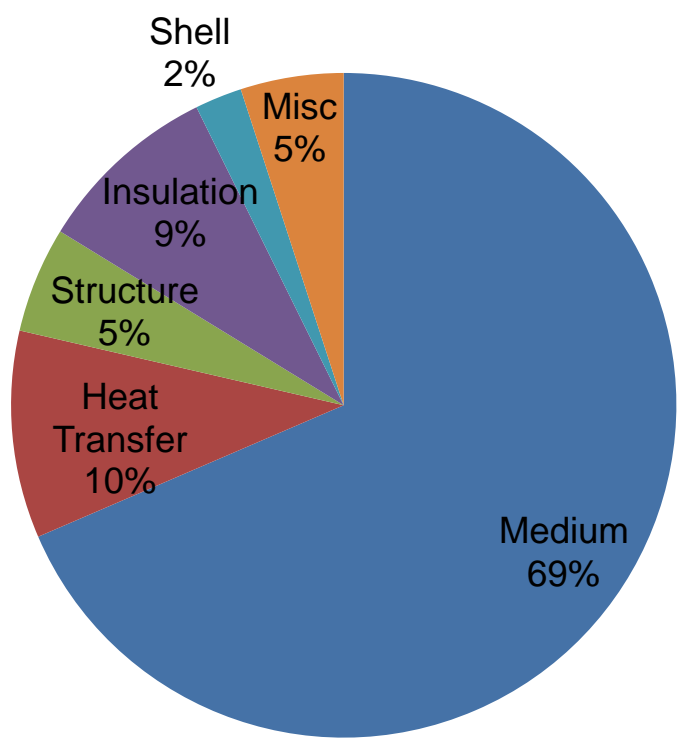

Component volumes

Figure 10 System weight and volume distribution 

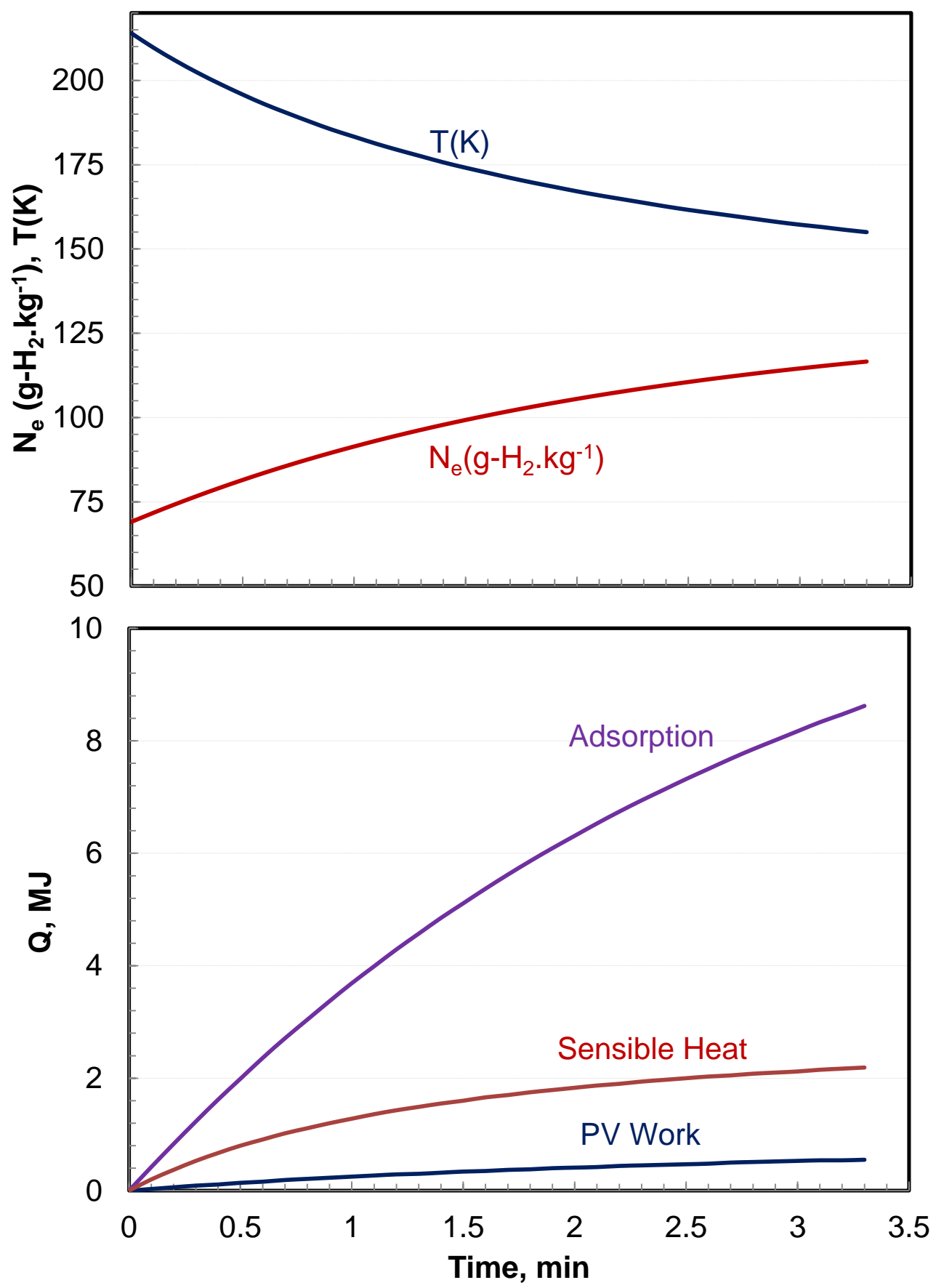

Figure 11 Hydrogen uptake and heat transfer during a typical refueling event 

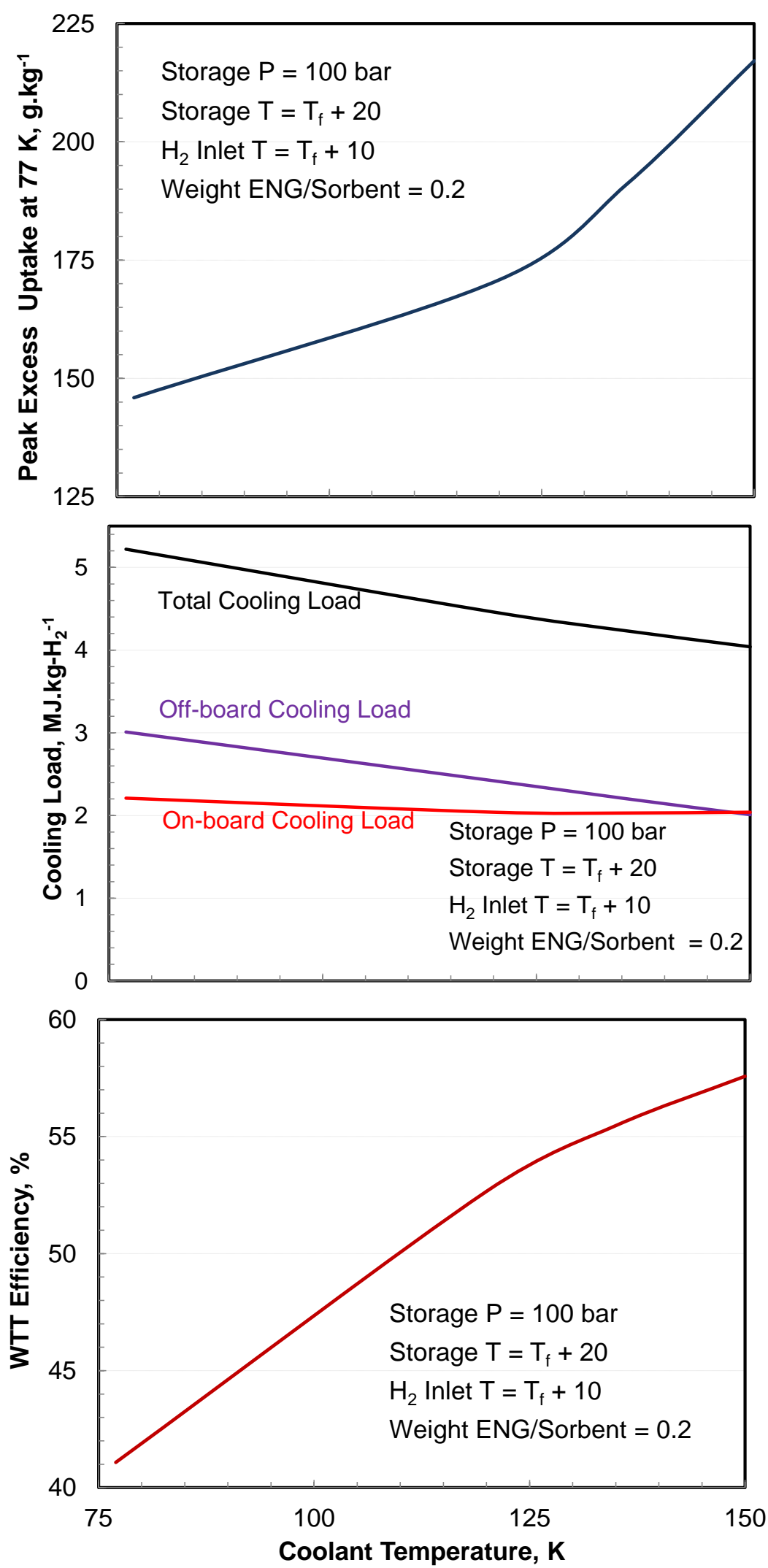

Figure 12 Coolant temperature sensitivity study 


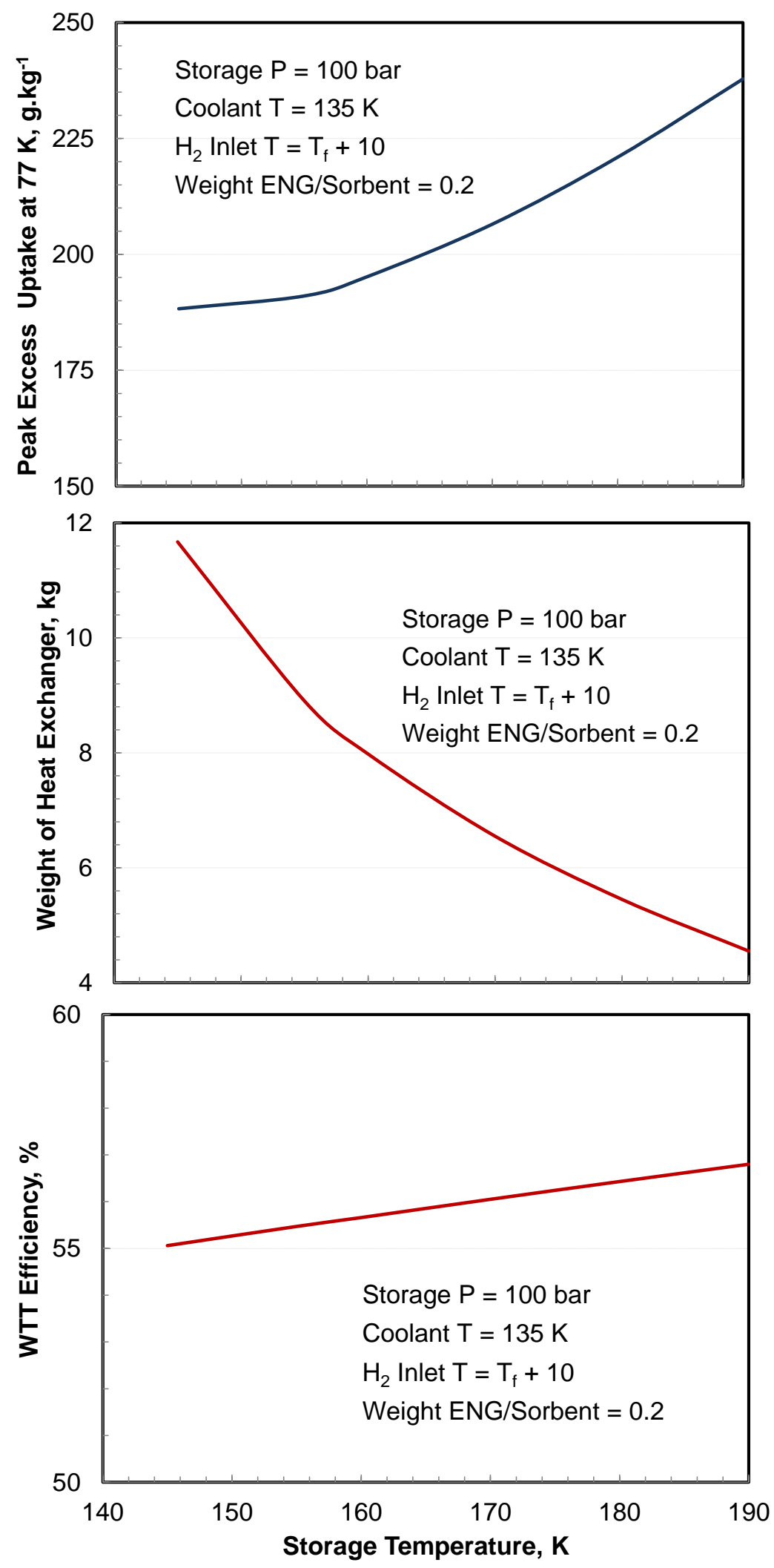

Figure 13 Storage temperature sensitivity study 

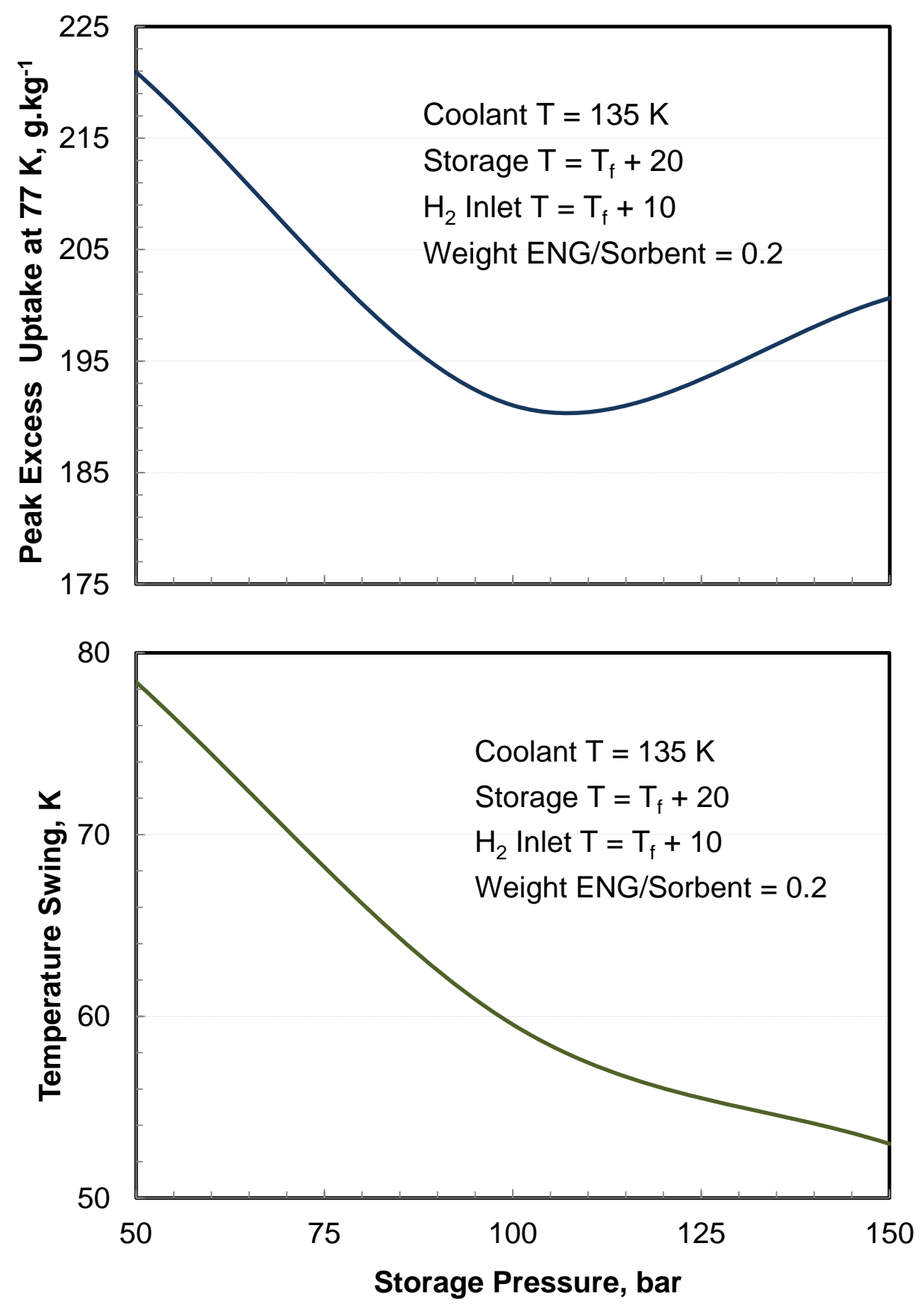

Figure 14 Storage pressure sensitivity study 


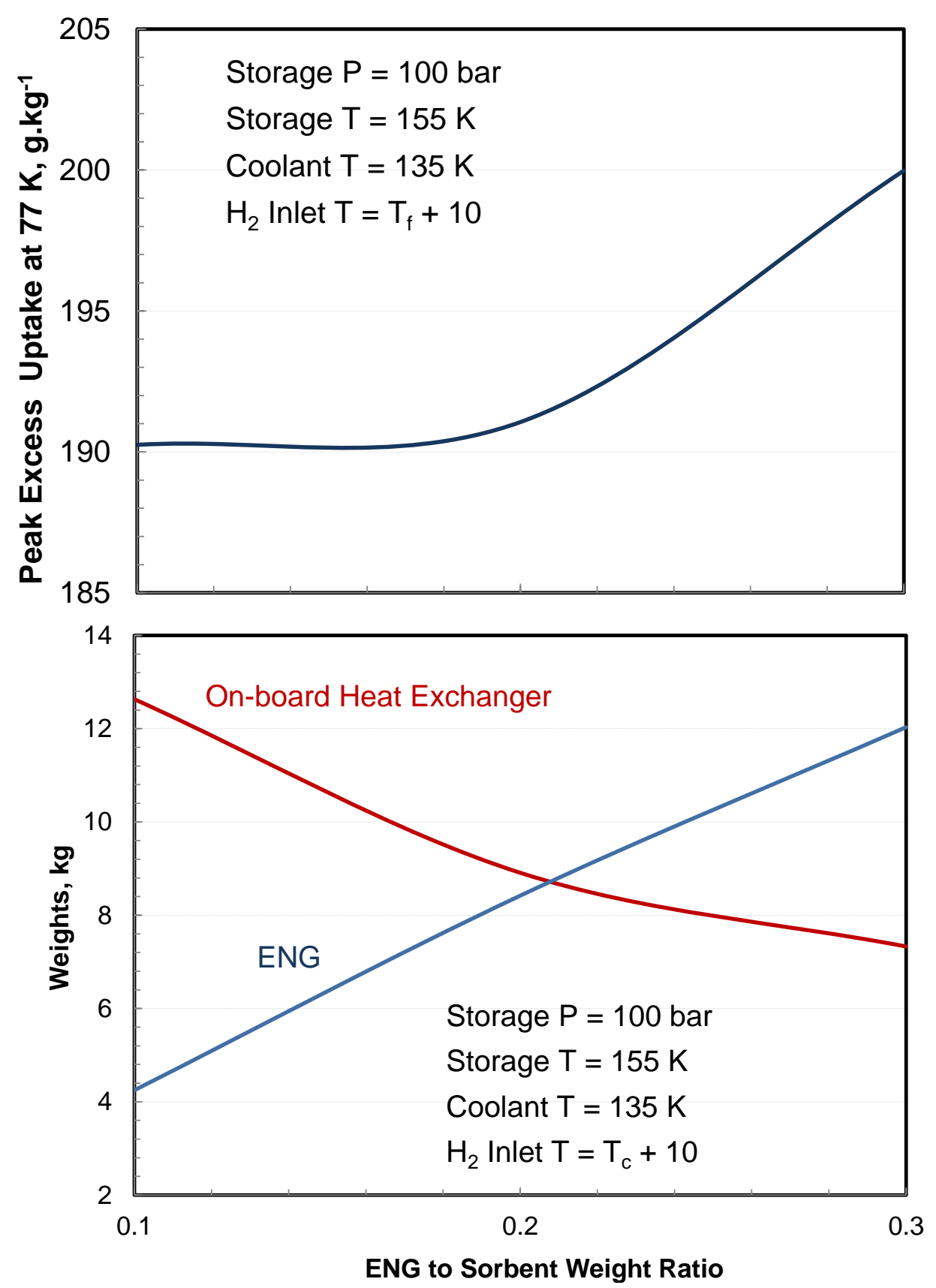

Figure 15 Thermal conductivity sensitivity study 


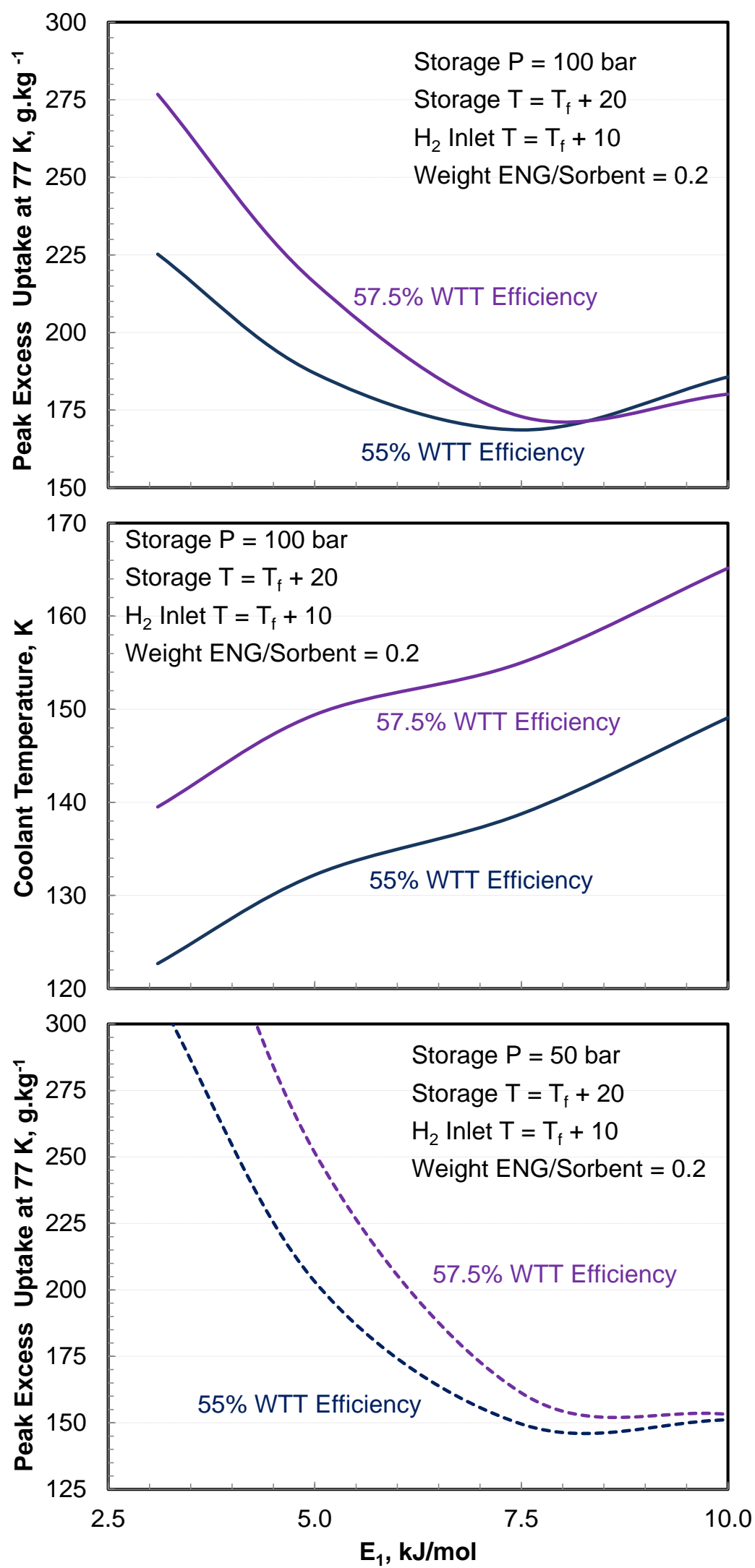

Figure 16 Adsorption enthalpy sensitivity study 


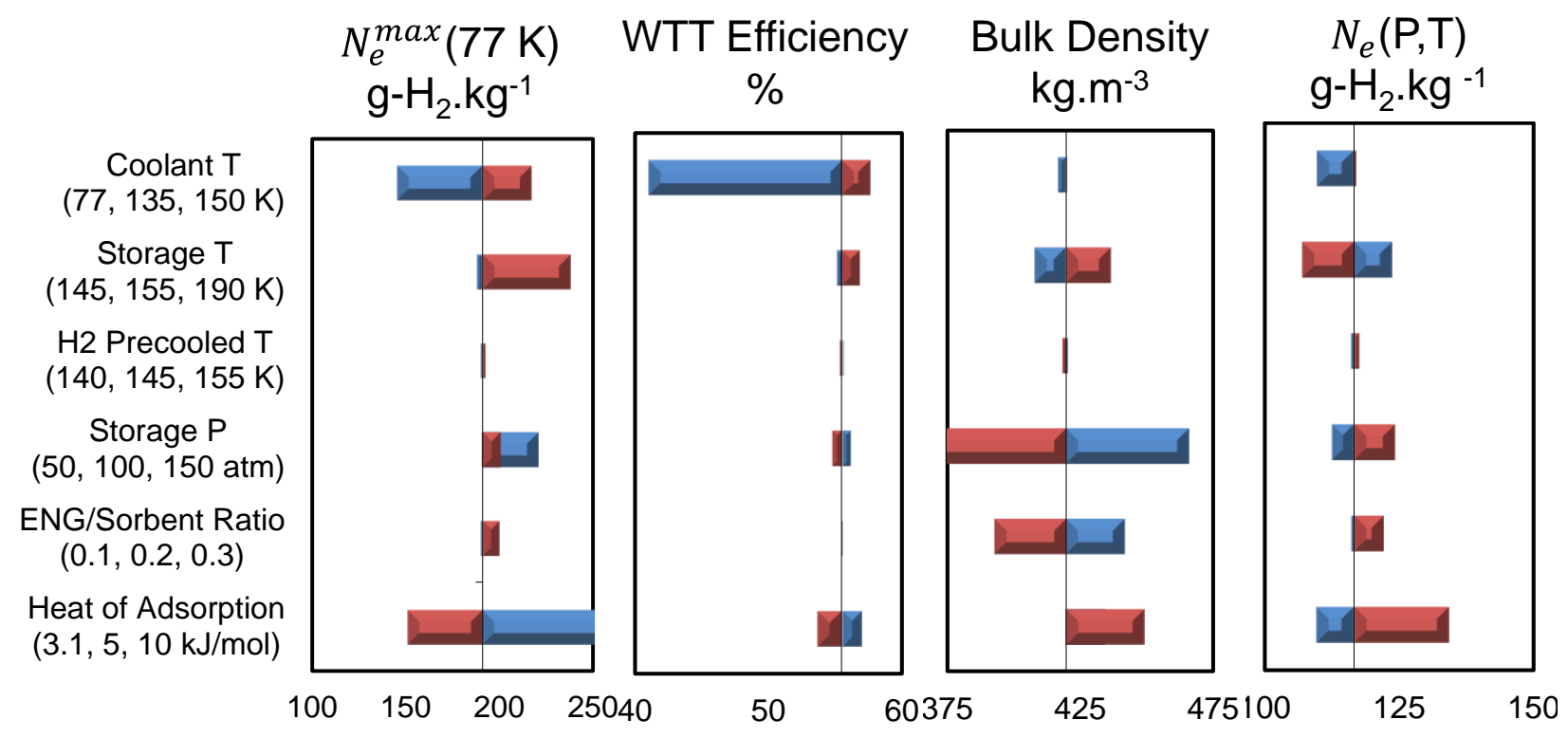

Figure 17 Summary of results of sensitivity studies 